\title{
La discriminación múltiple de las mujeres extranjeras que trabajan en servicios domésticos y de cuidados a dependientes en Euskadi ${ }^{1}$
}

\author{
Julia Nogueira Domínguez \\ Investigadora en políticas de igualdad \\ $<$ xuliand@gmail.com>
}

\author{
Joseba Zalakain Hernández \\ Director del SIIS Centro de Documentación, Fundación Eguía-Careaga
}

\begin{abstract}
Euskadin bizi diren migrazio-prozesuetan partaide izan eta etxebizitzetan mendetasun egoeretan dauden pertsonen zainketan lan egiten duten emakumeek aurre egin behar izaten diete bereziki larriak diren sexua, jatorri etniko eta etxebizitzako sektoreko lanaren adierazleak jatorri dituzten kalteberatasun eta diskriminazio egoerei, eta horien ondorioz, laneko prekarietatea bizi dute eta baliabide sozialak eta herritarren oinarrizko eskubideak lortzeko zailtasun eta desberdintasunak gertatzen dira. Arazo hori kontrastatu ahal izateko azterketak azaltzen duenez, ez da zuzenbide bakarreko ikerketa premiako duen arlo bat, izan ere, ondorengo askotariko kausa hauen tankerakoak agertzen dira arlo honetan: migrazio-prozesuen eboluzioa, etxeko lanen inguruko premia sozialak, egitura tradizionalaren rolen inguruko aldaketa eta zenbait politika publikoen funtzionamendua, adibidez, mendetasunaren inguruko politikak, atzerritarren inguruko arautegia eta etxebizitzetako jardueretako enpleguaren erregulazioa.
\end{abstract}

\section{GAKO-HITZAK:}

Emakumeen immigrazioa, diskriminazioa, mendetasuna, etxebizitzetako sektorea.
Las mujeres migradas que viven en Euskadi y que se dedican a actividades relacionadas con el cuidado de personas dependientes en los domicilios se enfrentan a situaciones de especial vulnerabilidad y discriminación, provocadas por las variables sexo, origen étnico y ocupación en el sector doméstico, y que implican precariedad laboral y desigualdad en el acceso a recursos sociales y a derechos básicos de la ciudadanía. El análisis realizado para el contraste de este supuesto indica que, lejos de tratarse de un ámbito de estudio unidireccional, constituye un fenómeno multicausal relacionado con la evolución de los procesos migratorios, las necesidades sociales en torno al trabajo reproductivo, el cambio de roles de la estructura tradicional de la familia y el funcionamiento de ciertas políticas públicas, como aquellas diseñadas en torno a la dependencia, o la legislación en materia de extranjería y la regulación del empleo ejercido en los hogares.

\section{Palabras Clave:}

Inmigración femenina, discriminación, dependencia, sector doméstico.

${ }^{1}$ Este artículo deriva del estudio La discriminación múltiple de las mujeres inmigrantes trabajadoras en servicios domésticos y de cuidados en la Comunidad Autónoma de Euskadi, financiado por Emakunde-Instituto Vasco de la Mujer en 2014 (Nogueira y Zalakain, 2015). 
Independientemente de que las personas tengan o no tengan papeles somos humanos y ser migrante no es un delito.

MUJER MIGRADA TRABAJADORA EN SERVICIOS DOMÉSTICOS Y DE CUIDADO

\section{Introducción}

En este artículo se analizan las características del trabajo de cuidados que, realizado en los hogares privados y contratado como servicio doméstico, se dirige a la atención de las personas dependientes. En concreto, estudiamos el proceso de inserción de las mujeres inmigrantes en esta actividad, a la sociedad y a los recursos sociales básicos en la comunidad autónoma de Euskadi, así como a la búsqueda de situaciones de desigualdad que podrían afectar a las mujeres extranjeras que se dedican al cuidado doméstico y de personas dependientes, que gira en torno a tres elementos fundamentales:

- El fenómeno conocido como crisis de los cuidados, provocado por un -débil y ficticioresquebrajamiento de la división tradicional de las obligaciones familiares, que encuentra como vía de escape la mercantilización y externalización del trabajo doméstico y de cuidado a personas dependientes.

- El diseño de las políticas públicas en materia de dependencia, que tratan de aliviar la presión ejercida por el envejecimiento de la población y la falta de conciliación de las familias, a través de prestaciones económicas y servicios públicos para el cuidado de la población con dependencias, así como su influencia en la externalización y etnoestratificación del cuidado.

- El estudio de las condiciones laborales de un sector -el doméstico-que empieza a visibilizarse en la legislación, pero que apenas ha comenzado su andadura en la equiparación con el resto de profesiones.

Desde el punto de vista metodológico, cuatro herramientas han ayudado a ofrecer un profundo análisis de la situación, desde las conclusiones ofrecidas por el amplio corpus científico publicado en torno al objeto de esta investigación, los resultados de la estadística oficial sobre los factores de influencia mencionados hasta las opiniones de las personas relacionadas con el objeto del estudio:

- La revisión del marco teórico, a través de una extensa selección de investigaciones sobre migraciones y protección a la dependencia, entre otros fenómenos.

- El desarrollo de un marco normativo, en el que se clasifica y analiza la legislación internacional, estatal y autonómica relacionada con el objeto de estudio.
- El análisis cuantitativo, a partir de la explotación de los datos ofrecidos por la estadística oficial publicada en materia de extranjería y el sector del cuidado en la comunidad autónoma de Euskadi.

- El análisis cualitativo, a partir de la realización entrevistas y grupos de discusión, con una selección de grupos de población relacionados directa e indirectamente con cualquiera de los factores que afectan a la investigación.

Así, a través de ellas, se ha llegado a conclusiones que corroboran la hipótesis de partida -el padecimiento de determinados procesos de discriminación que afectan de forma especial a la migración femenina dedicada al sector doméstico-, pero que abren otros frentes de análisis relacionados con el funcionamiento de la legislación y las políticas públicas en materia de dependencia y extranjería, las necesidades de atención de las familias, la etnoestratificación (Anderson, 2000) del empleo, y la profesionalización del trabajo doméstico y de cuidados en el entorno de los hogares.

\section{Marco teórico: cuidados, dependencia, inmigración, género y discriminación}

El estudio del sector doméstico está alcanzando una creciente importancia, tanto a escala nacional como internacional, en un contexto determinado por la progresiva mercantilización del trabajo reproductivo (Pla-Julián y Giménez-Moreno, 2012). El interés de analizar este fenómeno responde al impacto que un conjunto de factores como el envejecimiento de la población, la mayor participación de las mujeres en el empleo y las nuevas formas de convivencia en los hogares han tenido sobre la forma tradicional de proporcionar cuidados familiares. Pese a la introducción de la Ley de Dependencia y el desarrollo de los servicios sociales, ni los poderes públicos ni las organizaciones privadas han dado una respuesta suficientemente satisfactoria a la demanda de cuidados generada por parte de las personas dependientes y sus familias; de ahí que sigan siendo las personas del hogar, y especialmente las mujeres quienes, bien asumiendo el trabajo o bien externalizándolo mediante la contratación de cuidadoras inmigrantes, resuelven dicha demanda. El trabajo doméstico remunerado se ha convertido, pues, en una estrategia decisiva de la organización doméstica familiar y, sólo en parte, en objeto de atención y regulación por parte de las políticas públicas (García Sainz et al., 2014).

En ese contexto, la provisión de cuidados a las personas mayores dependientes por parte de mujeres inmigrantes -ya sea contratadas de forma regular o irregular- está convirtiéndose, sobre todo en los países del sur de Europa, en una de las fórmulas más habituales para dar respuesta a las necesidades que plantean los nuevos escenarios sociodemográficos -envejecimiento e incorporación de la mujer al mercado de trabajo, fundamentalmente $-\mathrm{y}$ a las 
limitaciones de los Estados del bienestar del sur de Europa para dar respuesta a esas necesidades (León, 2013; Pavlou, 2011).

A parir de estas tesis, el análisis de este fenómeno debe ser necesariamente multidimensional, ya que inciden en él cuestiones tales como:

- La distribución internacional del trabajo en el marco de la globalización y su traslación a las políticas de regulación migratoria.

- Las desigualdades de género en la asignación de las tareas productivas y reproductivas en el seno de las sociedades desarrolladas y en el contexto de la economía del cuidado.

- La existencia de pautas de estratificación social, en virtud de las cuales las mujeres cuidadoras inmigrantes se convierten en el soporte que las familias autóctonas precisan para poder conciliar sus responsabilidades familiares y laborales, especialmente en los casos en los que se plantea la necesidad de atender a una persona mayor dependiente.

- Las situaciones de desigualdad, explotación o discriminación en el acceso a los derechos y a los recursos sociales que pueden experimentar las mujeres inmigrantes que desempeñan estas tareas.

- La naturaleza mixta de los cuidados a las personas dependientes, en la que se entremezclan los aspectos emocionales, los relacionados con las obligaciones afectivas y familiares, y los que cabe considerar como estrictamente técnicos o profesionales.

- La regulación del mercado laboral y la extensión de la economía irregular o sumergida.

- Los diferentes modelos existentes en cuanto a la provisión de servicios públicos y privados de atención a la dependencia.

Así, el objetivo de la elaboración del marco teórico es el de recoger y sistematizar las aportaciones de los trabajos de investigación realizados, preferentemente en el Estado español, en relación con estas cuestiones. Se ha intentado, en definitiva, presentar el contexto en el que se inserta la investigación a escala estatal, con el objeto de ubicar los datos y las reflexiones que se derivan del análisis cuantitativo y cualitativo posteriores, referidos a la comunidad autónoma de Euskadi (CAE).

\section{LA EXTERNALIZACIÓN DEL CUIDADO DOMÉSTICO Y}

FAMILIAR. La primera idea que el análisis de la literatura publicada pone de manifiesto es el cambio de roles dentro de las familias, consecuencia de la entrada de todas las personas en edad activa del hogar al trabajo remunerado, y de la consiguiente necesidad de externalización de los cuidados domésticos en los países de nuestro entorno, es decir, la búsqueda, por parte de las familias, de alternativas que permitan suplir el trabajo reproductivo que previamente realizaban las mujeres. Esta situación, conocida como crisis de los cuidados (Orozco, 2007), empuja a las familias a buscar en el exterior -en los servicios formales o informales, públicos o privados, regulares 0 irregulares- la respuesta a unas necesidades que previamente satisfacían, fundamentalmente, las mujeres del hogar, de manera que el trabajo doméstico sigue formando parte de la esfera privada, en la medida en que la responsabilidad de los cuidados continúa ejerciéndose en los hogares, pero trasladada a manos externas.

\section{LAS POLÍTICAS PÚBLICAS Y SU EFECTO EN LAS CONFIGURACIONES DE LOS CUIDADOS. Tal} externalización no se da, sin embargo, de la misma forma en los distintos países de Europa. Mientras que en algunos países se traduce en un recurso creciente a los servicios sociales públicos, en otros se basa en el acceso al mercado privado de cuidados. Este mercado privado de cuidados tiene en algunos países carácter formal y regular (mediante empresas y agencias de contratación), mientras que en los países del sur de Europa el recurso a las mujeres inmigrantes se convierte en una de las estrategias más frecuentes para esa externalización.

La opción por un modelo u otro está política y socialmente condicionada por la adopción de una serie de medidas concretas en materia de políticas de atención a la dependencia, regulación de los flujos migratorios, del trabajo doméstico y de la economía sumergida. Como explica Martínez Buján (2011) para el caso español, “una cultura del cuidado fuertemente familista, una protección social débil y reforzadora de la parentela como proveedora, y una escasa asunción de responsabilidades domésticas por parte de los hombres han repercutido en la aparición de una estrategia de externalización individualista pensada desde y para la familia. La reorganización de los cuidados se centra en los recursos que ofrece el mercado privado y no pasa ni por un reparto más adecuado de las tareas entre hombres y mujeres (mitigando así la división sexual y generacional de estas labores), ni por una reivindicación de mejorar la protección social”.

\section{LA INICIATIVA MIGRATORIA FEMENINA Y LA} FORMACIÓN DE CADENAS GLOBALES DE CUIDADO. Se establecen así unos flujos migratorios cualitativa y cuantitativamente distintos de los existentes durante la mayor parte del siglo XX, que conforman lo que en la literatura especializada se conoce como cadenas globales de cuidado (Orozco, 2007), y que se basan en una distribución desigual del trabajo reproductivo, tanto desde el punto de vista del origen nacional como de la clase y del género. Las mujeres inmigrantes se incorporan así a un sistema que funciona a escala internacional, y que les reserva el papel de cuidadoras o sirvientas, de la misma manera que, a través de la deslocalización de las empresas manufactureras occidentales, tiende crecientemente a asignar a hombres y mujeres de los países pobres la función de producir bienes de consumo a bajo coste. 
En este contexto, los cuidados familiares se han convertido en un nicho privilegiado de empleo para las mujeres inmigrantes, especialmente las de origen latinoamericano, en España, el trabajo de cuidados se ha convertido para ellas en la puerta de entrada al mercado laboral español (Martínez Buján, 2011; Climent, 2010; Rodríguez et al., 2010).

\section{EL TRABAJO DE LA MIGRACIÓN FEMENINA Y LA} INTERSECCIONALIDAD DE LA DISCRIMINACIÓN. La mayor parte de los estudios que inciden en las situaciones de desigualdad, exclusión o discriminación que sufren las mujeres inmigrantes que se dedican al trabajo de cuidados, enfocan esta cuestión desde la intersección de, al menos, tres variables: migración, género y trabajo de cuidados. En ese sentido, autoras como Pavlou (2011) recuerdan que, "como mujeres, se trata de personas condicionadas por sesgos de género, estructuras patriarcales y un entorno social y político opresor. Como extranjeras, pueden sufrir adicionalmente problemas de racismo o xenofobia, debido a su origen étnico, su color, su religión u otros elementos, así como limitaciones en sus derechos sociales, políticos, civiles, económicos y culturales debido a su estatus jurídico y a la aplicación de políticas migratorias restrictivas. Finalmente, como trabajadoras domésticas, están confinadas en la esfera privada que supone el hogar de las personas que las emplean, sometidas a menudo a condiciones laborales deficientes y con escaso acceso a los sistemas de inspección y salvaguarda de sus derechos". También para Hrženjak (2011) el concepto de interseccionalidad -la forma en que las desigualdades producidas por motivos de género, origen y clase social se relacionan y retroalimentanresulta clave para cualquier análisis de la cuestión del trabajo doméstico irregular y la feminización de la pobreza o la exclusión social.

Cabe hablar, por tanto, como han señalado diversas autoras (Parella, 2003; Gil Araujo y González, 2012), de un "trasvase de desigualdades entre mujeres, en las que a la estructura de la desigualdad de género se superponen las desigualdades de raíz étnica y socioeconómica. De este modo, se enmascara el mito del nuevo igualitarismo dentro de la pareja, mientras que el patriarcado sigue subyaciendo inalterado detrás de las estructuras domésticas y del empleo remunerado. Las trabajadoras inmigrantes actúan como un ejército de reserva periférico que permite abaratar el coste de los servicios vinculados a la reproducción social tanto para el capital como para el Estado, a costa de aumentar las desigualdades sociales entre las mujeres" (Parella, 2003).

\section{LA PRECARIEDAD E IRREGULARIDAD DEL SECTOR} DOMÉSTICo. La mayor parte de los estudios realizados en el Estado español sobre el sector doméstico desde la perspectiva de las relaciones laborales, lo vinculan a la economía sumergida y al empleo informal, atendiendo, entre otros aspectos, a los bajos salarios, las jornadas laborales excesivas, la escasa cobertura legal y protección social de las personas que lo desempeñan (García Sainz, 2014).
Efectivamente, la inmensa mayoría de los estudios analizados inciden en que las trabajadoras del servicio doméstico se ven expuestas a situaciones de inestabilidad laboral, bajos ingresos, ausencia de prestaciones sociales, marginalización e intensas jornadas laborales que determinan agotamiento, aislamiento social, y escasas oportunidades para la formación y la capacitación en sus puestos de trabajo. Estos aspectos se han visto intensificados por estar al margen de la Seguridad Social y, en el caso concreto de las inmigrantes, agravados por su estatus migratorio (Briones et al., 2014).

\section{El CARÁCTER 'ESPECIAL’ DEL TRABAJO DE CUIDADOS: ENTRE LO PROFESIONAL, LO DOMÉSTICO, LO AFECTIVO} Y LO EMOCIONAL. Para entender adecuadamente el trabajo de cuidados domésticos que realizan las mujeres inmigrantes en nuestro contexto es importante tener en cuenta, tal y como hacen muchos de los trabajos revisados, dos elementos básicos: el cuidado y el domicilio. Emerge así en la literatura, por una parte, la cuestión de la mezcla entre lo profesional o técnico y lo emocional o afectivo (cuestión que se relaciona también, claramente, con la desigualdad de género que subyace a estas relaciones laborales).

Martínez-Buján (2008) explica de qué forma la literatura feminista británica desarrolla, a partir de los años ochenta, el concepto care, que en castellano puede traducirse como “cuidar", y que representa al conjunto de actividades que tienen como finalidad paliar el deterioro físico y psicológico de aquellas personas que no pueden valerse por sí mismas. En primera instancia, explica la autora, el concepto aparece rodeado de una polémica que intenta averiguar si el cuidado puede ser equiparado a un empleo formal, puesto que en su interior operan vínculos de cariño y afecto que difícilmente pueden traducirse en un salario. Sin embargo, esta perspectiva es pronto superada por otra que incluye el concepto de cuidados que se desarrolla por parte de personas que no tienen vínculos familiares, sino laborales, con las personas atendidas.

Así, siguiendo con la explicación de Martínez-Buján, a lo largo de la década de los noventa es cuando se desarrollan relevantes avances en la definición del concepto “cuidar”. El objetivo analítico es conseguir un término que incluya los distintos componentes de la actividad del cuidado y que pueda extenderse a todos los agentes de provisión asistencial. El debate, al igual que en los años ochenta, gira en torno a los aspectos de afecto y trabajo que se superponen en la actividad de cuidar y se centra en averiguar si el trabajo de cuidado remunerado está desprovisto o no de "amor". Subyace en todo caso en relación con esta discusión el carácter mixto de este tipo de trabajos, en los que lo afectivo y lo emocional son difíciles de separar de lo estrictamente técnico o profesional. 


\section{Marco normativo: la regulación de la extranjería, la dependencia y el sector doméstico}

El carácter normativo de muchos de los elementos señalados implica necesariamente un análisis de la legislación, no sólo en materia de extranjería, sino también de las políticas públicas que han querido dar respuesta a la crisis de los cuidados y a la visibilización y dignificación del sector doméstico, del que se extraen conclusiones relevantes que atañen a la CAE, respecto al comportamiento de las familias en el contexto de la externalización de los cuidados, la calidad de vida de la inmigración y a las condiciones del trabajo en el interior de los hogares.

\section{LA INFLUENCIA DEL SISTEMA DE PROTECCIÓN SOCIAL} EN LA ELECCIÓN DE LOS SERVICIOS DE CUIDAdOS A PERSONAS DEPENDIENTES. En un sistema en el que la familia ocupa la posición central de la atención a sus miembros dependientes, la influencia de la legislación estatal y autonómica en materia de cuidados en el modo de externalización del servicio (formal/informal, domiciliario/residencial) va a resultar crucial, de ahí el análisis de la Ley de Promoción de la Autonomía Personal y Atención a las personas en situación de Dependencia estatal (39/2006) y la Ley vasca de Servicios Sociales (12/2008). Estas dos normativas ofrecen recursos que intentan resolver el desequilibrio entre el tiempo dedicado al trabajo productivo y reproductivo, que irrumpe en los hogares y que provoca, en gran medida, la mencionada externalización de los cuidados de las personas dependientes en manos de personas ajenas a las familias y otros servicios de atención. Así, a través de la redacción de estas leyes, se dicta una nueva configuración de la atención a las personas con dependencias, protagonizada por la oferta de servicios públicos (servicios residenciales y centros de atención) y prestaciones económicas del Sistema para la Autonomía y Atención a la Dependencia (SAAD), que van a determinar la elección de la contratación privada de personas cuidadoras en los hogares - a través de prestaciones económicas-o de recursos de atención formales externos al hogar.

\section{LA CALIDAD DE VIDA Y TRAYECTORIAS DE LAS MUJERES CUIDADORAS, CONDICIONADAS POR LA REGULACIÓN DE LOS FLUJOS MIGRATORIOS. LaS condiciones vitales de las personas migrantes en los países de destino, y concretamente de la inmigración femenina, van a estar marcadas por la regulación de la extranjería en cada país. Esta normativa va a determinar su acceso al empleo, a otros recursos sociales y a la participación sociopolítica de las personas recién llegadas.}

Atendiendo a las trayectorias migratorias, se ha analizado la Ley Orgánica 4/2000, de 11 de enero, sobre Derechos y Libertades de los Extranjeros en España y su Integración Social, que dicta diferentes modalidades de consecución de residencia temporal en territorio estatal para personas migradas desde fuera de las fronteras europeas. La más frecuente, a tenor de las intervenciones en el trabajo de campo cualitativo realizado en Euskadi, es la denominada "arraigo social", que implica el empadronamiento durante tres años consecutivos en la región de destino y el contrato laboral con un salario no inferior al mínimo interprofesional, entre otras obligaciones. Dicho empadronamiento es una condición importante si se tiene en cuenta, por un lado, el acceso a diferentes recursos sociales que concede este trámite administrativo, y por otro, porque supone un requisito imprescindible para poder solicitar la primera autorización de residencia. Pero también lo es el acceso al trabajo, que asegurará la obtención de recursos de subsistencia, y que realizan de manera precaria al menos durante los tres primeros años de residencia en el país.

Dichas condiciones van a afectar de manera muy significativa, por tanto, a las trayectorias - entrada, inserción en el empleo, estabilidad económica, tiempo de estancia- de las mujeres de origen extranjero dentro de las fronteras tanto españolas como vascas.

\section{EL CARÁCTER ESPECIAL Y LA REGULACIÓN LABORAL DE LOS SERVICIOS DOMÉSTICOS Y DE ATENCIÓN A LA} DEPENDENCIA. Hasta 2011, la norma que regía el empleo de las personas trabajadoras del sector doméstico era el Real Decreto 1424/1985, “que regula la relación laboral de carácter especial del servicio doméstico". A partir de entonces, el trabajo doméstico (y el de cuidado en los hogares por una persona contratada de manera particular por la familia) ha evolucionado en la forma, pero no en el fondo. Así, el preámbulo del nuevo Real Decreto 1620/2011 "por el que se regula la relación laboral de carácter especial del servicio de hogar familiar” continúa justificando, al igual que el anterior, la especificidad de estas relaciones laborales ya que, según su redacción: “Las condiciones particulares en que se realiza la actividad de las personas que trabajan en el servicio doméstico, que justifican una regulación específica y diferenciada son bien conocidas", reafirmando la invisibilidad: “El ámbito donde se presta la actividad, el hogar familiar, tan vinculado a la intimidad personal y familiar y por completo ajeno y extraño al común denominador de las relaciones laborales, que se desenvuelven en entornos de actividad productiva presididos por los principios de la economía de mercado", y la ambigüedad en las condiciones laborales: "El vínculo personal basado en una especial relación de confianza que preside, desde su nacimiento, la relación laboral entre el titular del hogar familiar y los trabajadores del hogar, que no tiene que estar forzosamente presente en los restantes tipos de relaciones de trabajo".

Además, existen en este empleo determinados hándicaps (García Sainz, 2014) como la ausencia de protección por desempleo, un aumento del coste de las cotizaciones a la Seguridad Social en los primeros tramos, la desprotección de la persona trabajadora 
discontinua y la ambigüedad en el establecimiento de las tareas a realizar en el hogar.

\section{EL ACCESO A LOS RECURSOS SOCIALES DE} LA POBLACIÓN EXTRANJERA A TRAVÉS DEL EMPADRONAMIENTO. Respecto al nivel de acceso a los derechos sociales básicos, hay que decir que el empadronamiento constituye un requisito imprescindible para algunos de los derechos sociales básicos, como la educación y la sanidad, y que las barreras a la hora de su consecución son mayores para las mujeres que trabajan en los domicilios ya que, si se unen la dificultad de acceder a una vivienda propia en la que registrar su estancia al empleo en condición de interna (según la cual vive y trabaja en el domicilio de la persona dependiente), se incrementa la situación de vulnerabilidad, a causa de la temporalidad del trabajo y de la consiguiente posible pérdida del domicilio.

En el marco de la CAE, el acceso a los servicios sociales y a la renta de garantía de ingresos (RGI) de las personas inmigrantes viene determinado por la Ley $18 / 2008$, de 23 de diciembre, para la Garantía de Ingresos y para la Inclusión Social (modificada por la Ley 4/2011, de 24 de noviembre, de modificación de la Ley para la Garantía de Ingresos y para la Inclusión Social). Esta norma regula la percepción RGI y otros derechos como el acceso a la vivienda, mejora los procesos de inclusión, y define los programas y servicios de inclusión social y laboral.

\section{Externalización de los cuidados en el domicilio y condiciones de vida de las cuidadoras inmigrantes: una perspectiva cuantitativa}

A partir del marco teórico y normativo, se ha realizado un exhaustivo análisis de las fuentes estadísticas que aportan información sobre, por una parte, la externalización de los trabajos reproductivos en la CAE y, por otra, las condiciones laborales y de vida de las personas que trabajan en ese sector, incidiendo, siempre que ello ha sido posible, en las mujeres inmigrantes o nacidas en el extranjero y que residen en Euskadi. El análisis realizado consta de dos partes, que corresponden a los dos grandes interrogantes a los que se quiere dar respuesta:

- La evolución del empleo en el servicio doméstico y de cuidados en Euskadi a lo largo de los últimos años. Este primer interrogante quiere confirmar en qué medida los problemas de conciliación de los tiempos laboral remunerado, doméstico y personal, y el envejecimiento de la población, han dado pie a un recurso más intenso que en el pasado a este tipo de servicios, en la línea de la externalización a la que antes se hacía referencia. En este epígrafe, por tanto, no se distingue el trabajo de cuidados realizado por mujeres, ni por mujeres inmigrantes, y se analiza básicamente la extensión de este tipo de servicios en términos de ocupación, afiliación a la Seguridad Social, contrataciones, valor de la producción y remuneración agregada. El desarrollo de este tipo de servicios se compara con el de los servicios sociales formales, con y sin alojamiento, con el objeto de analizar si el desarrollo de éstos afecta, positiva o negativamente, al empleo en el servicio doméstico.

- También se ofrecen datos respecto a la contratación de cuidadores o cuidadoras por parte de personas en situación de dependencia (o de sus familias), y la relación que puede existir entre la percepción de las prestaciones económicas que contempla la Ley de Dependencia y la extensión de este tipo de cuidados.

- Cuantificación de las mujeres inmigrantes que realizan este tipo de trabajos en Euskadi y descripción de sus condiciones vitales y laborales. Desde ese punto de vista, se analizan cuestiones relacionadas con el nivel de integración en la sociedad vasca de las mujeres inmigrantes que trabajan en el servicio doméstico, sus condiciones laborales, el nivel de acceso a prestaciones y a servicios sociales, las razones y condiciones en las que se produjo el proceso de emigración, la experimentación de situaciones de racismo y xenofobia, 0 las relaciones con la población autóctona, comparando la situación de estas mujeres con la del conjunto de las mujeres inmigrantes que trabajan en Euskadi.

Para realizar ese análisis, se ha recurrido a una decena de operaciones estadísticas diferentes, entre las que destaca el Censo del Mercado de Trabajo, la Encuesta de Necesidades Sociales y la Encuesta de Población Inmigrante en Euskadi, todas ellas realizadas por el Órgano Estadístico Específico del Departamento de Empleo y Políticas Sociales del Gobierno Vasco, a quien agradecemos la ayuda prestada.

No es sencillo - dada la diversidad de fuentes utilizadas, y sus resultados no siempre coincidentes- sintetizar las conclusiones que se derivan de este análisis cuantitativo. De hecho, si hay una conclusión básica que cabe extraer del análisis realizado es la dificultad que las fuentes estadísticas tienen para describir de forma coherente las cuestiones relacionadas con las mujeres que trabajan en el servicio doméstico, tanto en lo que se refiere a su cuantificación como a su caracterización. La segunda gran conclusión es que, a tenor de los datos recogidos, las condiciones laborales y de vida de estas mujeres sólo en parte responden a lo descrito en la literatura científica y, como se verá más adelante, al discurso de los agentes consultados. En ese sentido, el análisis cuantitativo pone de manifiesto una situación algo más positiva de lo esperado, tanto en lo que se refiere a las condiciones laborales como a los niveles generales de integración y de acceso a recursos sociales. Si bien ello no 


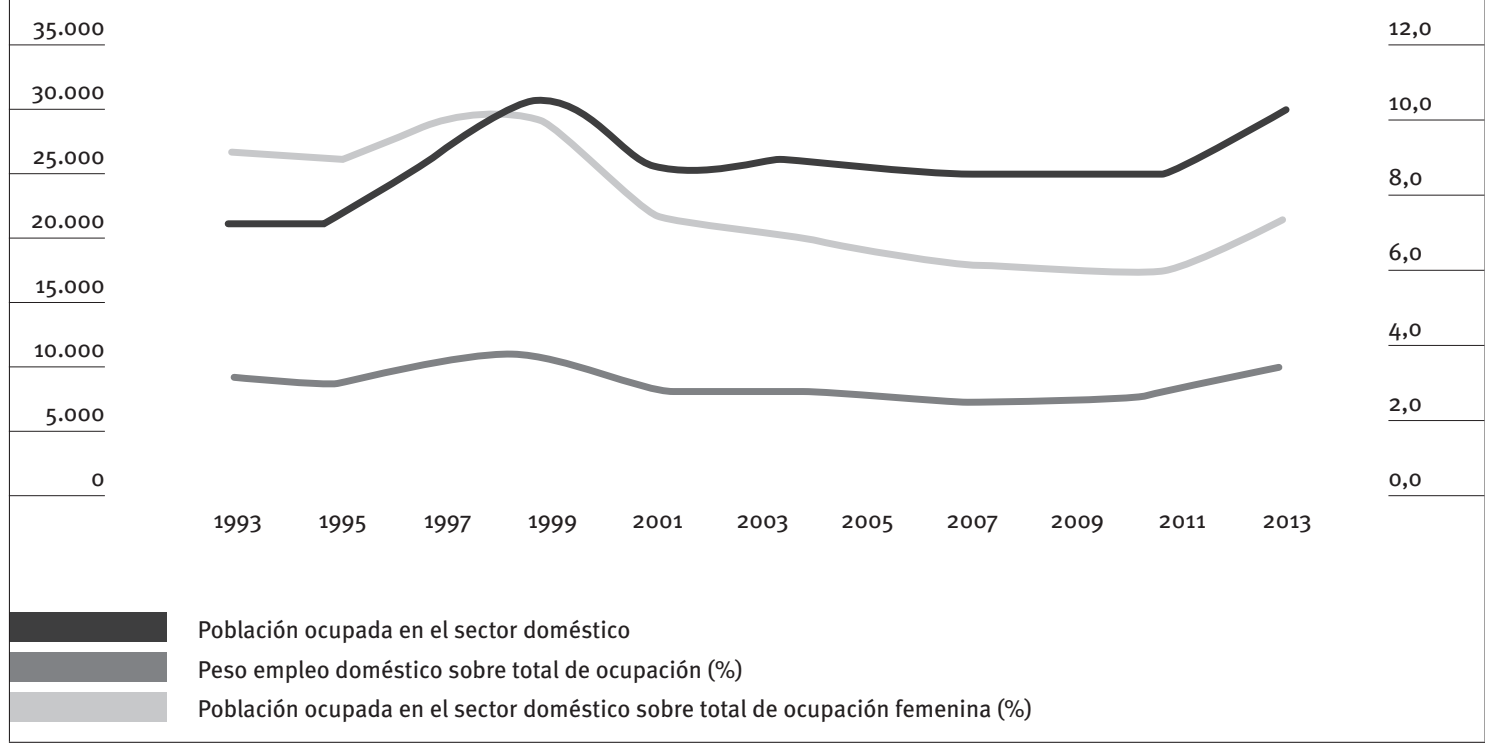

Fuente: Censo del Mercado de Trabajo (Órgano Estadístico Específico del Departamento de Empleo y Políticas Sociales). En este caso, el Censo recoge el empleo en el servicio doméstico propiamente dicho, incluyendo tanto el realizado con contrato como el realizado sin que medie contratación formal.

impide hablar de discriminación múltiple, pone de manifiesto la necesidad de tener en cuenta la diversidad interna de este colectivo. En todo caso, cabría destacar los siguientes datos:

\section{TENDENCIA AL CRECIMIENTO de LA OCUPACIÓN} EN EL SECTOR DOMÉSTICO. Una de las fuentes de datos que ofrece información a largo plazo sobre la evolución del empleo en el sector del servicio doméstico en Euskadi es el Censo del Mercado de Trabajo (Gráfic01). De acuerdo a esta fuente, no parece haberse producido un incremento lineal de la ocupación en esta actividad a lo largo de los años, sino, en todo caso, una pérdida de peso de este tipo de empleo entre 1999 y 2001, a la que seguiría una estabilización y una tendencia al crecimiento entre 2011 y 2013. De hecho, el peso de este tipo de actividad, tanto en lo que se refiere al conjunto del empleo como al empleo femenino, alcanza su grado máximo a finales de los años 90; si bien en 2013 los niveles son muy similares a los de aquella época (3,3\% del empleo total y $7,2 \%$ del empleo femenino).

\section{EL SERVICIO dOMÉSTICO Y DE CUIDADOS EN EUSKADI} ESTÁ CLARAMENTE FEMINIZADO. Las mujeres representan, de acuerdo a la Encuesta de la Población en Relación con la Actividad (Eustat), el $95 \%$ de todas las personas ocupadas en este sector y el número de mujeres ocupadas en el sector representa el $7,5 \%$ de la población ocupada femenina, por el 3,7\% de la población ocupada total.

Tampoco deja lugar a dudas la contextualización de los datos de la CAE en el entorno europeo. Si los resultados que la Encuesta de Población Activa arroja se comparan con los de la European Labour Force Survey de Eurostat, se observa que Euskadi está a la cabeza, junto a España, Italia y Portugal, en lo que se refiere al peso del servicio doméstico sobre el conjunto del empleo femenino.

\section{EUSKADI, A LA COLA DE EUROPA EN EL PESO DE LOS EMPLEOS EN LOS SERVICIOS SOCIALES SOBRE EL} SERVICIO DOMÉSTICO. Mientras que en Noruega por cada empleo en el sector doméstico hay 176 personas empleadas en los servicios sociales -en Dinamarca, 105; en Países Bajos, 95; en Alemania, 9,6; y en la UE-15, 4,6-, en la CAE la ratio es de 0,7 empleos en los servicios sociales por cada empleo en el sector doméstico (Gráfico 2).

As, la comunidad autónoma de Euskadi, que cuenta con un sistema de servicios sociales, en principio, sustancialmente diferente del de los países del sur de Europa ${ }^{2}$, comparte con ellos el elevado peso de este tipo de empleos. Hay que decir además que existen otros elementos de las políticas de servicios sociales - regulación de los flujos migratorios y del empleo doméstico, patrones culturales en cuanto a la distribución del trabajo reproductivo, por ejemploque estarían detrás de estas diferencias.

2 Según la literatura consultada para la elaboración del marco teórico, el modelo vasco de protección a la dependencia se caracteriza por contar con una situación equilibrada entre la participación de los Servicios Sociales, las prestaciones económicas y la contratación de cuidadoras no profesionales, al que la literatura llama "modelo opcional” (Martínez Buján, 2014), pero que no inhiben la demanda de cuidadoras en el régimen doméstico, sino que registran los porcentajes más elevados de contratación de empleadas de hogar. Sin embargo, los países del Sur de Europa se corresponden con el "modelo mediterráneo" (Van Hooren, 2012), que cuenta con un desarrollado sistema de prestaciones económicas sometido a escasos controles por parte de los Servicios Sociales. 


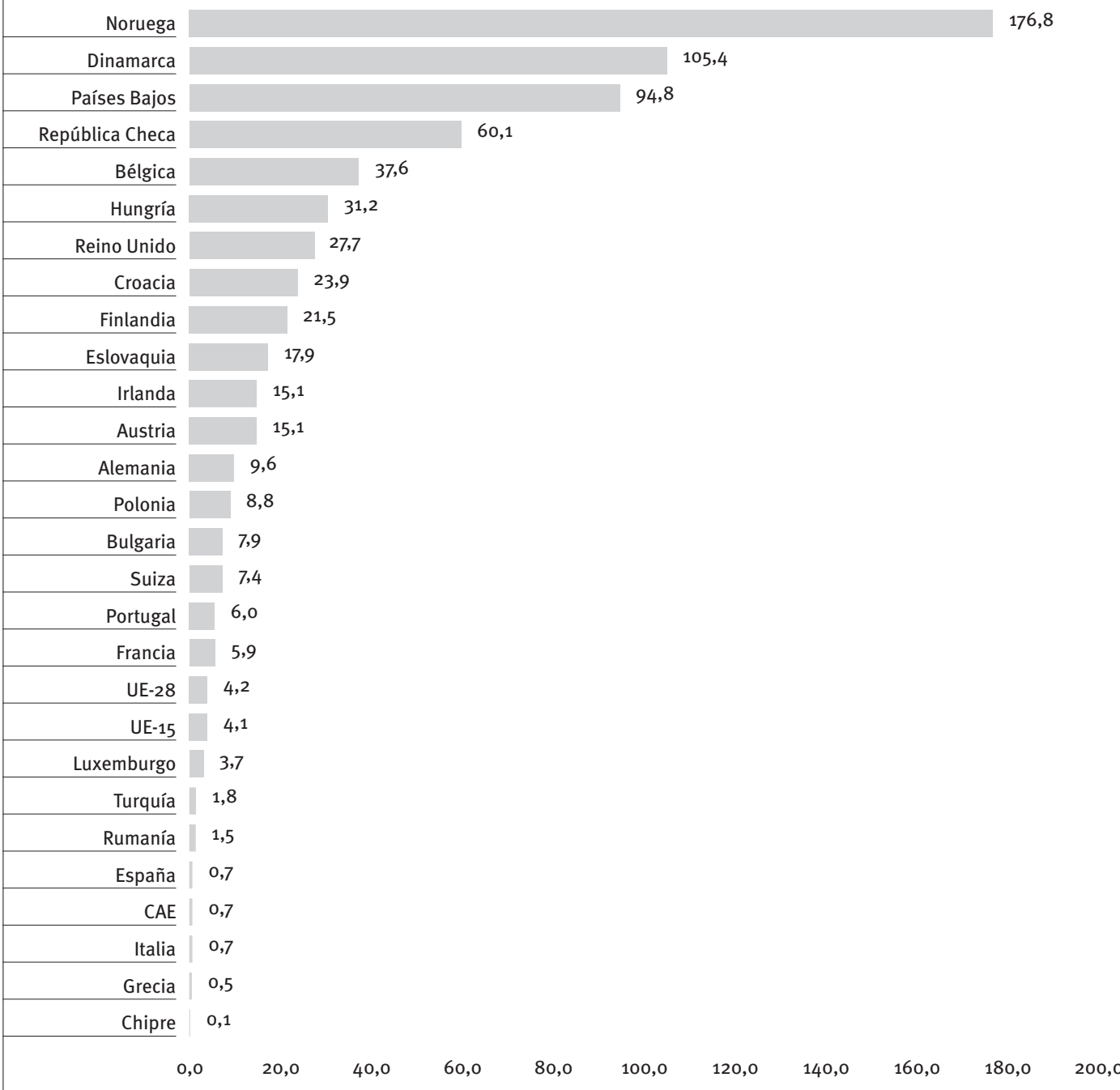

Fuente: Elaboración propia a partir de datos de la Encuesta de la Población en Relación con la Actividad 2014 (Eustat) para Euskadi y la European Labour Force Survey (Eurostat) para la UE.

\section{RALENTIZACIÓN DEL RECURSO dE LAS PERSONAS} CON DEPENDENCIA A CUIDADOS PARTICULARES. De acuerdo a los datos provisionales de la Estadística de Demanda de Servicios Sociales, en 2014 estarían atendidas por un cuidador o cuidadora contratada de forma particular algo más de 18.000 personas, que representan el $16 \%$ de las personas que precisan algún tipo de ayuda y el $30 \%$ de quienes la reciben, dado que el $52 \%$ de las personas con dependencia no reciben ninguna ayuda externa a la que encuentran en su domicilio (Tabla 1). Contra lo que cabía esperar, el recurso de las personas con dependencia a los cuidados particulares se ha reducido en los últimos años: tras crecer en un $50 \%$ entre 2006 y 2010 - pasando de 21.000 personas a 31.000-, se reduce a 18.000 en 2014 . Si en 2006 recibían este tipo de cuidados el $18 \%$ de todas las personas con necesidades de ayuda, en 2010 el porcentaje creció hasta el $25 \%$ para reducirse en 2014 al $16 \%$. Por otra parte, no se ha encontrado relación alguna entre la percepción de las prestaciones económicas del sistema de atención a la dependencia y el recurso a los cuidados contratados de forma particular.

\section{LA REGULACIÓN DEL EMPLEO A PARTIR DE LA} APLICACIÓN DEL REAL DECRETO 1620/2011 BENEFICIA MÁS A MUJERES AUTÓCTONAS QUE MIGRADAS. En el conjunto de la CAE, entre 2008 y 2013 , el número de mujeres extranjeras afiliadas a la Seguridad Social en alta en el régimen especial de trabajadoras del hogar se ha incrementado en un $51 \%$, pasando de poco más de 6.500 a casi 10.000 (Tabla 2). Pese al crecimiento en términos absolutos, el peso de estas personas sobre el total de personas afiliadas a la Seguridad Social en dicho régimen se reduce notablemente en este periodo, pasando del $54 \%$ en 2011 al $37 \%$ en 2013. La razón radica en que el 
Tabla 1. Población con dependencia especial que es atendida por una persona contratada de manera privada en los hogares, por grado de dependencia mixta Barthel/Lawton. CAE, 2006, 2010 y 2014

\begin{tabular}{|c|c|c|c|c|c|c|c|}
\hline & \multirow{3}{*}{$\begin{array}{c}\text { Total o grave } \\
9.182 \\
\end{array}$} & \multirow{3}{*}{$\begin{array}{c}\text { Moderada } \\
3.941 \\
\end{array}$} & \multirow{3}{*}{$\begin{array}{l}\text { Leve } \\
6.471\end{array}$} & \multirow{3}{*}{$\begin{array}{c}\text { Autónomo } \\
1.483\end{array}$} & \multirow{3}{*}{$\begin{array}{c}\text { Menor 0-5. } \\
335\end{array}$} & \multirow{3}{*}{$\begin{array}{l}\text { Total } \\
21.412\end{array}$} \\
\hline & & & & & & & \\
\hline \multirow{3}{*}{2006} & $\begin{array}{l}\text { Viene una persona contratada } \\
\text { particularmente }\end{array}$ & & & & & & \\
\hline & $\%$ con necesidades & 25,3 & 17,6 & 16,4 & 8,5 & 16,5 & 18,2 \\
\hline & $\%$ atendidas* & 25,3 & 31,1 & 30,4 & 23,1 & 88,4 & 27,8 \\
\hline \multirow{3}{*}{2010} & $\begin{array}{l}\text { Viene una persona contratada } \\
\text { particularmente }\end{array}$ & 15.609 & 5.182 & 10.071 & 932 & o & 31.794 \\
\hline & $\%$ con necesidades & 32,5 & 26,2 & 22,1 & 10,6 & 0,0 & 25,6 \\
\hline & $\%$ atendidas* & 7,0 & 7,7 & 2,8 & 3,5 & 35,7 & 5,9 \\
\hline \multirow{3}{*}{2014} & $\begin{array}{l}\text { Viene una persona contratada } \\
\text { particularmente }\end{array}$ & 7.503 & 4.297 & 6.518 & 385 & o & 18.702 \\
\hline & $\%$ con necesidades & 18,9 & 18,0 & 15,8 & 3,9 & 0,0 & 16,1 \\
\hline & $\%$ atendidas* & 25,4 & 26,9 & 43,4 & 10,7 & 0,0 & 29,1 \\
\hline
\end{tabular}

* La variable de atención es una variable múltiple, razón por la que los porcentajes pueden sumar más de 100.

Fuente: Estadística de Demanda de Servicios Sociales-Encuesta de Necesidades Sociales (Órgano Estadístico Específico del Departamento de Empleo y Políticas Sociales).

Tabla 2. Personas trabajadoras extranjeras afiliadas a la Seguridad Social en alta laboral en el régimen especial de trabajadoras del hogar. CAE, 2008-2013

\begin{tabular}{|c|c|c|c|c|c|c|c|c|}
\hline \multicolumn{2}{|c|}{ Población extranjera } & \multirow{2}{*}{$\begin{array}{c}2008 \\
995\end{array}$} & \multirow{2}{*}{$\begin{array}{l}2009 \\
963\end{array}$} & \multirow{2}{*}{$\begin{array}{c}2010 \\
976\end{array}$} & \multirow{2}{*}{$\begin{array}{l}2011 \\
1051\end{array}$} & \multirow{2}{*}{$\begin{array}{l}2012 \\
1372\end{array}$} & \multirow{2}{*}{$\begin{array}{r}2013 \\
1.284\end{array}$} & \multirow{2}{*}{$\begin{array}{c}\% \Delta \\
\% 8-13 \\
29,0\end{array}$} \\
\hline \multirow{4}{*}{ Población afiliada } & Álava & & & & & & & \\
\hline & Bizkaia & 3.161 & 3.287 & 4.030 & 4.774 & 5.774 & 5.614 & 77,6 \\
\hline & Gipuzkoa & 2.379 & 2.492 & 2.507 & 2.678 & 3.093 & 3.000 & 26,1 \\
\hline & Total & 6.535 & 6.743 & 7.513 & 8.503 & 10.239 & 9.897 & 51,4 \\
\hline \multirow{4}{*}{ Distribución (\%) } & Álava & 62,51 & 58,89 & 59,11 & 60,64 & 53,66 & 39,75 & - \\
\hline & Bizkaia & 45,42 & 46,37 & 51,60 & 56,00 & 48,44 & 37,14 & - \\
\hline & Gipuzkoa & 48,64 & 47,26 & 47,78 & 49,88 & 45,64 & 36,02 & - \\
\hline & Total & 48,61 & 48,17 & 51,08 & 54,41 & 48,18 & 37,10 & - \\
\hline
\end{tabular}

Fuente: Tesorería General de la Seguridad Social.

crecimiento en el número de personas autóctonas afiliadas ha crecido en mucha mayor medida que el correspondiente a las mujeres extranjeras, especialmente en el momento del cambio de regulación derivado de la aplicación del Real Decreto $1620 / 2011$.

\section{EL NÚMERO DE MUJERES INMIGRANTES OCUPADAS EN} EL SECTOR DEL SERVICIO DOMÉSTICO ASCIENDE A ENTRE TRECE MIL Y QUINCE MIL EN 2013, UN $40 \%$ MÁS QUE EN 2009. Según el Censo del Mercado de Trabajo, el crecimiento en el número de mujeres inmigrantes ocupadas en este sector de actividad en Euskadi contrasta con una ligera reducción en la presencia de mujeres autóctonas. De esta forma, cabe pensar que las mujeres inmigrantes han ido ganando peso en los últimos cuatro años dentro del colectivo de las personas ocupadas en este sector, pasando de ser el $38 \%$ en 2009 - un porcentaje en sí mismo elevadoal $44 \%$ en 2013. La elevada presencia de mujeres inmigrantes en el servicio doméstico contrasta con su escaso (aunque creciente) peso en los servicios sociales formales.

LA PRINCIPAL OCUPACIÓN DE LAS MUJERES MIGRADAS A EUSKADI, ESPECIALMENTE DE LAS LATINOAMERICANAS, ES EL SERVICIO DOMÉSTICO. Si las mujeres extranjeras se consideran en su totalidad, el empleo en el servicio doméstico es su principal ocupación, ya que el $42 \%$ de ellas trabajan en este sector. Sin embargo, la realidad es diferente si se tiene en cuenta la procedencia geográfica de estas mujeres, puesto que los porcentajes son muy elevados entre las latinoamericanas -casi el $80 \%$ entre las mujeres paraguayas-, pero mucho más bajos entre africanas 0 asiáticas (Tabla 3). De hecho, casi el $75 \%$ de las mujeres extranjeras que trabajan en el sector del servicio doméstico proceden de América Latina, cuando apenas representan el $51 \%$ de las mujeres extranjeras residentes en Euskadi. 
Tabla 3. Población femenina de 16 a 65 años ocupada en el servicio doméstico. CAE, 2010 (\%)

\begin{tabular}{|l|c|c|c|c|}
\hline \multirow{2}{*}{ Nacionalidad } & \multicolumn{2}{|c|}{ Mujeres extranjeras } & \multicolumn{2}{c|}{ Mujeres nacionalizadas } \\
\cline { 2 - 5 } & \% Horizontales & \% Verticales & \% Horizontales & \% Verticales \\
\hline UE Occidental & 19,6 & 3,4 & 50,8 & 12,0 \\
\hline Rumanía y otros países de la UE Oriental & 39,1 & 11,3 & 0,0 & 0,0 \\
\hline Magreb & 8,8 & 0,8 & 0,0 & 0,0 \\
\hline Argentina, Chile, Uruguay & 18,8 & 1,9 & 4,9 & 2,0 \\
\hline Colombia, Ecuador, Perú & 43,7 & 20,8 & 28,3 & 48,6 \\
\hline Bolivia & 70,4 & 20,9 & 42,0 & 3,3 \\
\hline Paraguay & 78,7 & 13,2 & 72,2 & 2,5 \\
\hline Brasil, Venezuela, República Dominicana & 36,6 & 7,4 & 24,0 & 16,6 \\
\hline Resto de América Latina & 49,9 & 13,5 & 21,4 & 8,6 \\
\hline China & 0,0 & 0,0 & 0,0 & 0,0 \\
\hline Senegal & 6,1 & 0,1 & 0,0 & 0,0 \\
\hline Resto de África & 25,5 & 0,7 & 20,6 & 4,8 \\
\hline Resto del mundo & 40,4 & 6,1 & 18,5 & 1,7 \\
\hline Total & 42,6 & 100,0 & 24,1 & 100,0 \\
\hline
\end{tabular}

Fuente: Encuesta de Población Inmigrante en Euskadi, 2010 (Órgano Estadístico Específico, Departamento de Empleo y Políticas Sociales).

SE REDUCE EL PESO de LAS MUJERES INMIGRANTES OCUPADAS EN EL SERVICIO DOMÉSTICO SIN PERMISO DE TRABAJO Y CRECE LA CONTRATACIÓN REGULAR, AUNQUE EL PORCENTAJE DE MUJERES INMIGRANTES EMPLEADAS EN ESTE SECTOR Y QUE CARECEN DE CONTRATO SIGUE SIENDO MUY SUPERIOR A LA MEDIA. Parece haberse producido en los últimos años una mejora en la situación de las mujeres inmigrantes en lo que se refiere a la regularización de su contratación, ya que las asalariadas sin contrato han pasado de representar el $40 \%$ del colectivo en 2009 al $25 \%$ en 2013. Esta mejoría puede ser, de nuevo, una influencia del cambio de normativa que supuso la implantación del Real Decreto 1620/2011. No hay que olvidar, en todo caso, que el porcentaje de personas ocupadas sin contrato es, en el conjunto del tejido productivo vasco, del 1,4 $\%$-y del $14 \%$ para las mujeres autóctonas que trabajan en este ámbitocon lo que la tasa de no contratación sería para las mujeres inmigrantes que trabajan en el servicio doméstico 25 veces más elevada que para el conjunto de la población ocupada en Euskadi.

También es importante destacar el incremento en el porcentaje de mujeres inmigrantes ocupadas en el sector del servicio doméstico que tienen un contrato indefinido y el de las que cotizan a la Seguridad Social.

\section{SE MANTIENE LA BRECHA SALARIAL ENTRE LAS} MUJERES INMIGRANTES EN EL SECTOR DE LA ATENCIÓN DOMÉSTICA Y EL RESTO DE LA POBLACIÓN OCUPADA. en cuenta la dedicación horaria: los datos del Censo del Mercado de Trabajo ponen de manifiesto, en ese sentido, que la brecha salarial existente entre el servicio doméstico y el resto de la población ocupada es menor cuando se tiene en cuenta el salario hora que el salario mensual, lo que indica que las diferencias se deben en parte a la realización de jornadas más cortas y a una mayor extensión de la jornada parcial. En todo caso, es importante señalar que el trabajo de bajos salarios resulta particularmente prevalente en este sector. Si el empleo de bajos salarios se define como el correspondiente a un salario inferior al $75 \%$ del salario medio, el $53 \%$ de las personas asalariadas en el sector estaría en esa situación, frente al $20 \%$ para el conjunto de la población asalariada y el $25 \%$ en el caso de la población asalariada femenina (Tabla 4).

Tabla 4. Porcentaje de la población asalariada y asimilada en el servicio doméstico sobre el conjunto de la población asalariada. Peso del salario/hora inferior al $75 \%$ de la media*. CAE, 2004, 2009 y 2013

\begin{tabular}{|l|c|c|c|}
\hline Año & $\begin{array}{c}\text { Servicio } \\
\text { doméstico }\end{array}$ & $\begin{array}{c}\text { Conjunto } \\
\text { población } \\
\text { asalariada }\end{array}$ & $\begin{array}{c}\text { Población } \\
\text { asalariada } \\
\text { femenina }\end{array}$ \\
\hline 2004 & 54,7 & 21,2 & 29,4 \\
\hline 2009 & 51,9 & 13,4 & 17,3 \\
\hline 2013 & 53,4 & 20,8 & 25,7 \\
\hline
\end{tabular}

* Precios de 2013.

Fuente: Encuesta de Condiciones de Trabajo (Departamento de Empleo y Políticas Sociales).

ALGO MÁs de UN TERCIO de LAS MUJERES MIGRAdAS OCUPADAS EN EL SECTOR DOMÉSTICO REFIEREN PROBLEMAS RELACIONADOS CON LAS CONDICIONES DE TRABAJO, LA JORNADA LABORAL, EL SALARIO O EL CONTRATO. Menos frecuentes, aunque no desdeñables, son los problemas relacionados con la promoción, las responsabilidades y el trato recibido, así como la contratación irregular por deseo del empresario, la percepción de un salario inferior al de otras personas en el mismo puesto o la realización de jornadas de trabajo mayores que las establecidas en el contrato, que afecta en torno al $10 \%$ de estas mujeres (Tabla 5). 
Tabla 5. Mujeres inmigrantes que trabajan en el servicio doméstico y presentan diversos problemas laborales, por nacionalidad. CAE, 2010 (\%)

\begin{tabular}{|c|c|c|}
\hline Problemas laborales (\%) & Extranjeras & Nacionalizadas \\
\hline Problemas en las condiciones de trabajo & 37,5 & 35,4 \\
\hline Problemas en jornada, salario, contrato & 33,2 & 35,4 \\
\hline Problemas en promoción, responsabilidades y trato & 12,6 & 8,0 \\
\hline Trabajo en situación irregular por deseo del empresario/a & 11,5 & 26,0 \\
\hline Salario menor que el de otras personas en el mismo puesto & 11,1 & 13,8 \\
\hline Jornada de trabajo mayor que la del contrato o la habitual & 9,4 & 11,7 \\
\hline Obligación de meter horas extraordinarias & 8,6 & 2,3 \\
\hline No se cumple el derecho de descanso (días libres) & 6,9 & 5,0 \\
\hline Salario menor que el del contrato o el habitual & 6,6 & 8,1 \\
\hline Incompatibilidad para cuidar hijos e hijas & 5,4 & 6,6 \\
\hline Relegado/a a las peores tareas por ser extranjero/a & 5,2 & 0,0 \\
\hline Aislamiento social o rechazo por parte de compañeros/as de trabajo & 4,9 & 0,4 \\
\hline Imposibilidad de ascenso en la empresa por ser extranjero/a & 4,6 & 2,7 \\
\hline Trato humillante por empleadores o superiores & 4,3 & 4,9 \\
\hline Imposibilidad de asumir responsabilidades por ser extranjero/a & 4,2 & 2,7 \\
\hline Jornada de trabajo menor que la del contrato o la habitual & 3,3 & 5,8 \\
\hline Menores niveles de seguridad en el trabajo & 3,3 & 0,0 \\
\hline
\end{tabular}

Fuente: Encuesta de Población Inmigrante en Euskadi (Órgano Estadístico Específico del Departamento de Empleo y Políticas Sociales, 2010).

Tabla 6. Población inmigrante, según la existencia necesidades económicas. CAE, 2010 (\%)

\begin{tabular}{|l|c|c|c|c|c|}
\hline Necesidades económicas & $\begin{array}{c}\text { Mujeres } \\
\text { extranjeras servicio } \\
\text { doméstico }\end{array}$ & $\begin{array}{c}\text { Mujeres } \\
\text { nacionalizadas } \\
\text { servicio doméstico }\end{array}$ & $\begin{array}{c}\text { Mujeres } \\
\text { extranjeras } \\
\text { ocupadas }\end{array}$ & $\begin{array}{c}\text { Mujeres } \\
\text { nacionalizadas } \\
\text { ocupada }\end{array}$ & $\begin{array}{c}\text { Población } \\
\text { extranjera } \\
\text { (total) }\end{array}$ \\
\hline $\begin{array}{l}\text { Para cubrir necesidades } \\
\text { de alimentación, vestido, } \\
\text { calzado o vivienda }\end{array}$ & 20,74 & 12,94 & 17,81 & 15,87 & 29,11 \\
\hline $\begin{array}{l}\text { Para hacer frente a gastos } \\
\text { imprevistos }\end{array}$ & 36,10 & 46,90 & 30,76 & 25,09 & 31,09 \\
\hline Sin dificultades & 43,15 & 40,16 & 51,43 & 59,04 & 39,80 \\
\hline Total & 100,00 & 100,00 & 100,00 & 100,00 & 100,00 \\
\hline
\end{tabular}

Fuente: Encuesta de Población Inmigrante en Euskadi (Órgano Estadístico Específico del Departamento de Empleo y Políticas Sociales, 2010).

\section{UNA PARTE IMPORTANTE DE LAS MUJERES INMIGRANTES RESIDENTES EN EUSKADI QUE TRABAJAN EN EL SERVICIO DOMÉSTICO SE ENCUENTRA CON DIFICULTADES PARA HACER FRENTE A SUS NECESIDADES ECONÓMICAS. El $20 \%$ tiene problemas para cubrir sus necesidades básicas (alimentación, vestido, calzado o vivienda) y el $36 \%$ tiene dificultades para hacer frente a gastos imprevistos (Tabla 6). Con todo, también es importante señalar que en torno a un $40 \%$ no presentan dificultades económicas. De hecho, las mujeres inmigrantes que trabajan en el sector de los cuidados domésticos no experimentan situaciones de privación económica en mayor medida que el resto de las mujeres inmigrantes ocupadas o que el resto de la población extranjera.}

SEÑALAN NO TENER PROBLEMAS PARA INTEGRARSE CON PERSONAS AUTÓctonas. Algo más habituales son, sin embargo, las experiencias de racismo 0 xenofobia, aunque no puede decirse que las mujeres que trabajan en el sector de los cuidados domésticos las experimenten en mayor medida que el resto de la población inmigrante: el porcentaje de quienes no han experimentado estos problemas $-83 \%$ en el caso de las de nacionalidad extranjera y $77 \%$ en el caso de las nacionalizadas- es muy similar a la del conjunto de la población extranjera.

EL $28 \%$ DE LAS MUJERES EXTRANJERAS QUE TRABAJAN EN EL SERVICIO DOMÉSTICO SE SIENTEN NADA, MUY POCO O POCO INTEGRADAS EN LA SOCIEDAD VASCA. Se trata de un nivel de integración percibida inferior al del conjunto de las mujeres inmigrantes ocupadas, e inferior al del conjunto de la población extranjera, lo que pone de 
manifiesto el impacto de esta ocupación -o, quizá, de los factores sociales y demográficos que caracterizan a las personas que realizan esta ocupación- en los niveles de integración social percibida.

RELATIVO ACCESO A LOS SERVICIOS SOCIALES PÚBLICOS Y A LAS PRESTACIONES DE GARANTÍA DE INGRESOS

DE LA CAE. En ese sentido, un $22 \%$ de las mujeres extranjeras ocupadas en el servicio doméstico estarían en 2010 percibiendo la renta de garantía de ingresos (RGI), en el mismo porcentaje que el conjunto de la población extranjera y en un $50 \%$ más que el conjunto de las mujeres extranjeras ocupadas. Mayor es aún la tasa de acceso a los servicios sociales públicos, con quienes han mantenido algún contacto el $32 \%$ de las mujeres extranjeras que trabajan en el servicio doméstico, por sólo el $21 \%$ del conjunto de las mujeres migradas ocupadas.

\section{Trayectorias migratorias femeninas, inserción laboral y acceso a recursos sociales: Una perspectiva cualitativa}

La información obtenida a través del análisis del discurso de personas de diferentes perfiles, relacionados directa o indirectamente con el objeto de estudio, resulta básica para la consecución de los objetivos del análisis, ya que se basa en la experiencia y conocimientos de personas que se encuentran en contacto con la realidad de las mujeres migrantes y su relación con el mercado laboral, los servicios sociales o la calidad de los cuidados.

Para llevarlo a cabo, se han elegido técnicas que analizan la realidad que hay detrás de la estadística y de las conclusiones de otros estudios realizados sobre el tema: "en el caso del análisis cualitativo la aproximación a la metodología permite conservar el lenguaje original de los sujetos, indagar su definición de la situación, la visión que tiene de su propia historia y de los condicionamientos estructurales" (Ibáñez, 1979). Las herramientas a las que se ha recurrido han sido las entrevistas en profundidad y los grupos de discusión, que permitieron la obtención de información a partir de la aportación de personas de los siguientes perfiles, localizados en el conjunto de la CAE:

- Mujeres migradas ocupadas en el servicio doméstico y de cuidado a personas dependientes.

- Familias con personas dependientes a su cargo y usuarias de servicios de cuidado en el hogar.

- Personas representantes de asociaciones vinculadas a la migración femenina.

- Personal de referencia de empresas que proporcionan servicios de atención domiciliaria.

- Personal técnico de servicios y entidades sociales.

El interés en la selección de varios perfiles de población para la realización de las entrevistas radica en sus diferentes puntos de vista sobre los temas que se abordan en el proyecto. Se ha comprobado que, por ejemplo, la visión de las condiciones laborales en el sector de los cuidados, o la importancia de la formación para ejercerlos, es vista de manera diferente según cada uno de los colectivos. Aunque las diferencias de opinión también aparecen entre personas que pertenecen a un mismo perfil, el análisis se hace más operativo y la facilidad de comprensión es mayor analizando, uno por uno, los temas que se han tratado. Por eso, el desarrollo desde el punto de vista cualitativo sigue la misma línea que la establecida en el marco teórico y la perspectiva cuantitativa, de manera que las personas participantes, a las que se agradece su desinteresada colaboración, han aportado su conocimiento, principalmente, sobre los siguientes temas:

- Cuidados, migración y género.

- La externalización de los servicios de cuidado en los domicilios.

- Las condiciones del empleo en los hogares.

Así, a través de las opiniones expresadas en torno a estos temas, se extraen los elementos más relevantes:

\section{PROCESOS MIGRATORIOS DETERMINADOS POR DIFICULTADES, CIRCUNSTANCIAS Y TRAYECTORIAS CONCRETAS Y COMPARTIDAS. LOS relatos de} asociaciones vinculadas a la inmigración femenina en Euskadi dibujan un perfil concreto respecto a las mujeres migradas empleadas en los servicios domésticos y de cuidado a personas dependientes: madres - solteras, casadas con maridos en paro, víctimas de malos tratos-cada vez más jóvenes y sin trabajo, que abandonan sus países ante la imposibilidad de acceso al mercado laboral.

Evidentemente, hay una feminización de la inmigración desde hace bastante tiempo. Esa feminización está marcando, tanto en el país de origen como en el de llegada. Estamos hablando de mujeres que normalmente son bastante jóvenes; que normalmente tienen familia que, en un primer momento, se queda en origen; $y$ que cuando llegan aquí se insertan donde les permiten, normalmente en situación irregular. (Presidenta de asociación en favor de mujeres inmigrantes, Gipuzkoa)

Así, con respecto a la finalidad de sus procesos migratorios, se encuentra un nutrido grupo de mujeres que han emprendido su viaje solas, ante la imposibilidad de acceder a unos recursos económicos suficientes para su propio mantenimiento y el de sus familias y descendencia, a la que dejan al cuidado de otras mujeres, para ejercer tareas de atención a 'otras' personas dependientes de manera remunerada.

Además, estos proyectos siguen unos pasos muy concretos. En función de los resultados obtenidos 
a partir de los relatos de las mujeres migradas participantes, resultan los siguientes:

\section{- Organización logística y económica del viaje.} El trayecto hasta la entrada en Euskadi y la acumulación de recursos económicos para sufragar su coste ha sido objeto de conversación desde la perspectiva cualitativa, ya que muchas de las personas entrevistadas han afirmado que en la mayoría de los casos se asumen deudas con bancos o prestamistas para poder hacer frente al pago del pasaje y a los gastos iniciales previos a la consecución de un empleo.

El billete significa bajar de Nicaragua, ir a Salvador, a Holanda, París, Hendaya y después aquí, y para pagar ese billete, que te puede costar entre 2.000 y 2.500, y empeñas todo lo que tienes para adquirir una deuda. (Presidenta de asociación en favor de mujeres inmigrantes, Gipuzkoa)

- Empadronamiento e inserción laboral. Estos trámites representan el segundo paso en la trayectoria, porque son indispensables para obtener la regularidad administrativa en el territorio de destino. Por otro lado, el empleo será fundamental para la consecución del principal objetivo de estas mujeres, que no es otro que la mejora de sus propias condiciones vitales y las de su familia en el país de origen, a la que envían en muchas ocasiones remesas de dinero procedentes de su trabajo.

- Primera autorización de residencia. Una vez conseguidos los requisitos relacionados con el tiempo de estancia y con el trabajo, puede solicitarse la primera autorización de residencia: de esta manera, los tres o cuatro primeros años (en ocasiones incluso más) de estancia en Euskadi suponen una carrera hacia la búsqueda de un empleo y de la documentación para la autorización por "arraigo social”, que llega con un empadronamiento de tres años ininterrumpidos y un contrato de trabajo, ente otras condiciones.

Los trámites [para la regularidad] si la persona llega y en el minuto uno de llegar se empadrona, y tarda tres años para la regularidad, lo que normalmente solemos poner de punto de partida es el padrón, pero lo que pasa es que entre el momento de llegada y el padrón suele pasar bastante tiempo, porque hay bastantes dificultades para acceder a una vivienda, hay prejuicios con relación al alquiler de viviendas a personas inmigrantes. Hasta que la persona no encuentra una vivienda en la que pueda vivir y eso le genere el padrón, hasta ese momento, no existe; a partir del padrón, tres años hasta que puedes presentar la documentación, y a partir de allí, te puede tardar un añito o así: total, cuatro años. Hasta ese momento, has de tener tu vida empaquetada en una bolsa. (Persona técnica de entidad social, Bizkaia)

- Planes de futuro. A partir de las charlas con asociaciones y mujeres migradas cuidadoras residentes en Euskadi, puede decirse que se aprecian proyectos migratorios a corto/medio plazo, que terminarían en el momento en que las necesidades más urgentes de la familia que dejan en origen se solventasen, pero encuentran un factor que retrasa su vuelta: el objetivo de la regulación administrativa, que mejorará sus condiciones vitales y laborales. Estas afirmaciones, en cualquier caso, no eliminan otras situaciones en las que se toma la alternativa del establecimiento definitivo en Euskadi e incluso la reagrupación familiar.

ETNOESTRATIFICACIÓN LABORAL: EL SECTOR DOMÉSTICO COMO ÚNICA OPORTUNIDAD DE INSERCIÓN LABORAL EN EUSKADI PARA MUJERES DE CIERTAS NACIONALIDADES.

Que el empleo en este sector es casi la única oportunidad para las mujeres migradas es una realidad que se ha contrastado a partir de las entrevistas realizadas, y que se debe a las propias condiciones de precariedad de este tipo de trabajos, que provoca la imposibilidad de acceder a otros más profesionalizados y con mejores condiciones. De esta manera, el hecho de ser mujer, trabajadora e inmigrante, va a determinar la inserción laboral casi exclusiva en el sector doméstico y del cuidado que, debido a que se ha llevado a cabo tradicionalmente en el seno de las familias, de manera privada e invisible, es femenino, precario, y está poco dignificado y profesionalizado, quedando relegado a los grupos de población con menos recursos.
¿Cuáles son los sectores que están abiertos a las mujeres inmigrantes y a las regulares e irregulares? La reflexión es al revés: si eres irregular, no puedes estar en ningún puesto de trabajo, es el que está abierto. Lo que hay que hacer es que estas personas se incorporen a algo: está el empleo irregular y el sistema de protección social, que está aguantando la bolsa de trabajo sumergido, y no somos las personas inmigrantes las que lo estamos creando. (Persona técnica de entidad social, Bizkaia)

Sin embargo, no todas las mujeres de origen extranjero acceden en la misma medida a este tipo de empleos, sino que su entrada va a estar condicionada, además, por su nacionalidad. Así, durante el trabajo de campo, las propias mujeres entrevistadas pusieron de manifiesto la importancia de la valoración por parte de las familias de características - costumbres, cultura, aspecto físico- relacionadas con las nacionalidades de origen, mostrando siempre una preferencia clara por las mujeres latinoamericanas.

\section{FUENTES DE INFORMACIÓN INFORMALES Y ACCESO A} RECURSOS SOCIALES DETERMINADO POR EL PADRÓN. Con respecto al acceso en igualdad de condiciones que el resto de la población a derechos sociales básicos, se alude, en primer lugar, al hecho de que la información de los trámites de acceso a recursos sociales de las mujeres recién llegadas a Euskadi procede de fuentes no gubernamentales. Esta situación es preocupante para los servicios sociales 
del Gobierno Vasco, que relacionan la calidad de la información que poseen las personas extranjeras con la situación administrativa en la que se encuentran. Según este grupo, las personas con la primera autorización de residencia acceden a los servicios de información de sus departamentos, mientras que las que no lo han conseguido lo hacen mediante otras vías, como las entidades sociales y las amistades.

Por otro lado, esta dificultad de acceso a la información es un aspecto que va a afectar de manera especial a las mujeres extranjeras que se dedican al cuidado y al servicio doméstico, y especialmente a aquellas que trabajan en modalidad de interna, debido a que en este caso su residencia es al mismo tiempo su lugar de trabajo, circunstancia que implica una especial dificultad de conciliación entre empleo remunerado y tiempo personal, ya que impide la salida del hogar en los horarios en los que se puede acceder a las entidades que facilitan la información.

Es que no tiene nada que ver la situación de la mujer que trabaja de interna con la que trabaja externa por cuenta propia, con la que trabaja en una empresa: las condiciones de salir, informarse y acceder son diferentes. Discriminación tienen por mujeres y por extranjeras, desorientación y desconocimiento. Y cuanto menos tiempo libre tengan, mejor, para ganar el mayor dinero posible en menos tiempo. Cuando pasa el tiempo y pasan de ser interinas a externas, ya pueden tener tiempo libre. (Persona técnica de servicios sociales, Álava)

Además, se reconoce que la capacidad de acceso a los recursos sociales está directamente relacionada con la situación administrativa o, como mínimo, la posesión del certificado de empadronamiento. Esta es una conclusión para la que existe unanimidad, ya que el padrón es la puerta de entrada para la obtención de derechos (como la atención sanitaria y algunos servicios formativos), cuestión puesta de relieve tanto por los servicios y entidades sociales como por las asociaciones.

Lo primero que tienes que hacer para ayudarla, la principal dificultad cuando vienes es: vale, me empadrona una familia, y empiezo a trabajar en $B$, porque si la familia no cobra ayuda, muchas familias no hacen contrato, porque si la mujer vale y te dice que no la puedes contratar... Porque empadronar no es ilegal, mientras viva bajo el mismo techo. Hay veces que llegan chicas que llevan aquí siete años y que te dicen: "no estoy empadronada”. (Persona técnica de entidad social, Gipuzkoa)

Entre los servicios más demandados se encuentran espacios para el intercambio y la participación social. Así, las personas trabajadoras en los servicios sociales vascos hablan tanto de asesorías jurídicas gratuitas, que les informen sobre la Ley de Extranjería y sus derechos laborales, como servicios de alojamiento estable para cuando quieran reagrupar a sus hijos con ellas, entre otros. Sin embargo, el interés primordial se refiere a lugares donde acudir y establecer relaciones sociales en los momentos de tiempo libre, sobre todo para las mujeres recién llegadas y que trabajan en régimen de interna. Este recurso, que tiene más que ver con la creación de redes sociales y el establecimiento de vínculos que garanticen un bienestar más personal, y que resulta fundamental para la calidad de vida, es el que ofrecen, en gran medida, las asociaciones de mujeres inmigrantes.

Porque cuando salen de las casas [las mujeres contratadas en régimen de interna], ¿a dónde van? Reclaman una asociación para poder crear un espacio donde ir cuando no están en la casa en la que trabajan, el día que tienen libre pululan por la ciudad, pero no siempre es agradable. [Tienen] El locutorio, pero ellas lo que reclaman es un espacio en el que estar, donde puedan estar con otras mujeres, donde haya un microondas... Los centros cívicos no pueden ofrecer eso. Muchas veces van a casa de familiares y conocidos, pero con el tiempo comienza a haber conflictos (Persona técnica de servicios sociales, Álava).

\section{EL CAMBIO DE ROLES FAMILIARES Y LA DIFICULTAD DE CONCILIACIÓN SON LOS PRINCIPALES IMPULSORES DE LA EXTERNALIZACIÓN DE LOS SERVICIOS DE CUIDADO EN LOS DOMICILIOS EN EUSKADI. LaS} necesidades de atención por parte de las familias proceden de problemas relacionados con la falta de conciliación y la urgencia a partir de la aparición de enfermedades repentinas vinculadas a la edad. Estas cuestiones se han puesto de manifiesto en las entrevistas realizadas a empresas dedicadas a la asistencia domiciliaria, a entidades sociales asistenciales y a las propias familias, en las que se ha expresado, además de los problemas derivados de la falta de conciliación, el desconocimiento de las enfermedades crónicas que invalidan la capacidad de ejercer actividades de la vida diaria a las personas mayores, y la falta de recursos públicos relacionados con la dependencia. Se trata, por tanto, de una situación en la que las familias no pueden dedicar la cantidad de atención requerida por la persona mayor, o por los hijos e hijas; son parejas en las que las dos personas trabajan fuera de casa, o personas solas con padre, madre o descendencia a cargo, para las que la distribución del tiempo entre los espacios público y privado supone un problema.

El tipo de familia es de dos o tres hijos, pero que cada uno tiene su vida, y que sus padres están con un diagnóstico, con alzhéimer, por ejemplo. Dan una valoración de dependencia y acuden a nosotros, o a otros. (Persona técnica de entidad social, Gipuzkoa)

\section{Clara preferencia por los Servicios en el HOGAR FRENTE A LOS CUIDADOS RESIDENCIALES.} Con respecto a la preferencia entre los servicios existentes, se da una clara inclinación hacia la atención prestada en los domicilios mediante el empleo de personas de manera particular. A juicio de las personas trabajadoras de los servicios sociales 
vascos, esta preferencia responde, principalmente, al encarecimiento de los servicios formales y a su escasa flexibilidad horaria. Así, a la hora de valorar el funcionamiento de los servicios públicos, la mayor parte de las personas participantes en el trabajo de campo han cuestionado su eficacia respecto del coste de los servicios ofrecidos. Por otro lado, prestaciones económicas como aquella destinada a la asistencia personal (PEAP) ${ }^{3}$, que ofrece la posibilidad de contratar a una persona con una jornada superior y más flexible que la que corresponde al servicio de atención domiciliaria (SAD) público.

Hay más gente con cuidadoras privadas que con SAD, y cada vez más. Porque nosotros tenemos limitaciones, más de tres horas no podemos poner, y hay gente que necesita más horas. Luego tiene sus ventajas y sus inconvenientes: te cambian de auxiliar, no puedes elegir los horarios si no es para cuidados personales... (Persona técnica de servicios sociales, Gipuzkoa)

En este sentido, se traen además a colación otras razones para no elegir servicios residenciales, como la cercanía a la familia y el mantenimiento en la vivienda habitual de la persona dependiente, el sentimiento de culpa o la propia petición de las personas que reciben los cuidados. De esta manera lo exponen tanto familias como empresas suministradoras de cuidado y entidades sociales, que apuntan a otras posibles soluciones como la combinación de cuidados en el domicilio y la asistencia a centros de día.

Hay una preferencia a contratar internas que a la residencia, porque hay un apego a la familia. Es muy duro para los hijos no poder atender a los padres, dejarlos en una residencia produce una sensación de abandono. Ellos dicen que, antes de residencia, quieren que esté en casa, por calidad de vida, hasta que no puedan; hay un momento en el que ya no pueden estar en casa. (Persona técnica de entidad social, Gipuzkoa)

\section{EL IMPACTO DE LA CRISIS ECONÓMICA, LA REGULACIÓN DE LA EXTRANJERÍA Y LAS POLÍTICAS PÚBLICAS EN LA EXTERNALIzACión. Según las entidades sociales consultadas en Euskadi, así como en periodos anteriores a la crisis se reclamaba mano de obra para realizar labores de acompañamiento a personas mayores, en la actualidad la solicitud de servicios de cuidado se realiza cuando ya no queda más remedio, cuando aparecen enfermedades graves que provocan dependencias severas - alzhéimer, demencia- que las familias no pueden atender, y en muchos casos}

3 Esta prestación económica está “destinada a la asistencia personal, durante un número de horas, que facilite al beneficiario el acceso a la educación y al trabajo, así como a una vida más autónoma en el ejercicio de las actividades básicas de la vida diaria" (Ley de Dependencia, art. 19). La aplicación de esta prestación es casi nula en el resto de las comunidades autónomas, ya que en estas se exige que la persona perceptora esté realizando actividades laborales o educativas, restricción que no se contempla en la CAE, pudiendo beneficiarse de ellas todas las personas con cierto grado de dependencia. cuando los niveles de dependencia son tan altos que las hacen perceptoras de prestaciones económicas que las ayudan a costear el servicio.

Del lado de las políticas públicas, la Ley de Extranjería estaría fomentando el empleo en la economía sumergida. Durante las entrevistas se ha afirmado que los intentos de restringir la entrada a personas de países extracomunitarios y el endurecimiento de las condiciones para adquirir la autorización de residencia no están contribuyendo necesariamente al descenso de la inmigración, pero sí a la prolongación de la irregularidad administrativa de las personas inmigrantes, que al entrar por la fuerza en un mercado laboral sumergido, carecen de derecho a un contrato, y sufren mayor vulnerabilidad respecto a la precariedad laboral y social. De esta manera, después de la regularización masiva, y con la restrictiva legislación actual, los empleos en el servicio doméstico y de cuidado siguen existiendo, pero en condiciones de invisibilidad e irregularidad.

Porque cuando tengas a más gente sin derechos reconocidos, esa bolsa [estará] más dispuesta a hacer cualquier cosa, cosa que es totalmente contraproducente para el Estado, porque si los regularizas, cotizan, como ha ocurrido aquí, donde todas esas bolsas de gente en situación documental irregular trabajaban. Pues regularízalas, que coticen y así la caja común será más amplia, y tendrán muchísimos más derechos, tendrán un contrato. (Persona técnica de servicios sociales, Álava)

En todo caso, se tiene en cuenta la contribución de determinadas prestaciones económicas a la formalización de contratos. Es posible que en Euskadi se estén dando pasos en favor de la visibilización y de la disminución de la economía informal en el ámbito del cuidado en los domicilios, a través del impulso de la PEAP. Esta prestación es de una cuantía sensiblemente superior a otras, y obliga a la contratación legal y el alta y cotización a la Seguridad Social, de manera que los beneficios económicos convencen a las familias perceptoras a formalizar la relación laboral.

\section{EL CARÁCTER, LA CULTURA Y LA EXPERIENCIA EN EL EJERCICIO DE LABORES DOMÉSTICAS, LA PREFERENCIA DE LAS FAMILIAS VASCAS. Las características} asociadas a la personalidad, el sexo y la nacionalidad, son variables consideradas de interés para la selección de las personas cuidadoras. Así se otorga, en primer lugar, gran importancia a los valores personales que tienen que ver con la responsabilidad, la confianza, la experiencia y la amabilidad en el trato, sin embargo, las competencias profesionales están asociadas, fundamentalmente, con el sector doméstico, es decir, la habilidad con la cocina, la compra de medicamentos y la limpieza.

Cocina, y cocina muy bien, es un estilo de Bolivia, pero muy bien, y lleva la casa. Lo habitual, diría 
que es limpiar, cuidar y curar, porque se atreve con cosas médicas, las heridas, los problemas de la piel... cubre todos los ámbitos [...]. Lo que es determinante es que funcionen según la cultura, tiene que manejarse con las farmacias y el médico, por eso la percibo más como ama de llaves. (Familia empleadora de cuidadora inmigrante, Gipuzkoa)

En segundo lugar, la preferencia por cuidadoras autóctonas se ha subrayado en múltiples ocasiones durante la exploración cualitativa, aunque se asegura que es una característica difícil de encontrar. Asumida esa limitación, la preferencia por cuidadoras latinoamericanas se muestra clara, por cuestiones como el idioma, la cultura o incluso la imagen personal.

Preferíamos que fuese una mujer de cierta edad y con carácter, y nos dimos cuenta de que el papel sudamericano sería el adecuado, más que una marroquí, que por el perfil cultural no iba a ser el más adecuado. Con las latinoamericanas es más fácil, porque la cultura es la misma. (Familia empleadora de cuidadora inmigrante, Gipuzkoa)

Por último, hay que insistir en la feminización del sector de los cuidados, ya que las familias - y en cierto modo también las empresas- tienden a buscar preferentemente a mujeres para el servicio de cuidado de personas dependientes y del hogar, justificado por la supuesta experiencia adquirida por estas en sus propios hogares, y por las capacidades asociadas al rol femenino. Aunque en algunas ocasiones se alude a una capacidad mayor de los hombres desde el plano físico, beneficioso según las personas entrevistadas en los casos en que las personas dependientes tienen problemas de movilidad, en la mayor parte de los casos se menciona el nivel de intimidad entre la persona cuidadora y cuidada para atribuir la preferencia por mujeres.

¿Sexo? Mujer, yo eso lo tengo superclaro, pues no sé por qué, no dejaría... igual es machista, o igual hay hombres que les cuidarían mucho mejor, pero no lo veo, porque como aquí vemos que los hombres no se ocupan, las que se encargan de los deberes son mujeres... Aunque haya hombres maravillosos, no es lo habitual. (Familia empleadora de cuidadora inmigrante, Bizkaia)

Preferencia por el nivel de presencia en el hogar QUE POR LABORES ESPECIALIZADAS. LOS ServicioS de cuidado ejercidos por mujeres externas a la familia en el domicilio son valorados según criterios diferentes por familias, empresas, entidades y servicios sociales en Euskadi. El motivo reside en la importancia que se da a la presencia, normalmente por parte de las familias, en contraposición con la necesidad de capacitación y formación en el área sociosanitaria expresado por empresas y servicios sociales, que destacan su influencia en el mantenimiento de la salud de personas con enfermedades especialmente complicadas.
Así, por lo que respecta a las opiniones de las familias, hay que decir que la valoración general de la calidad del servicio prestado es positiva, determinada probablemente por la urgencia de cubrir una necesidad de cuidado muy intensivo. En este sentido, la presencia y la flexibilidad de las mujeres inmigrantes a las que emplean son muy bien valoradas, y a éstas se unen otras más vinculadas con el servicio doméstico como la cocina, la limpieza, o el ejercicio de labores sociosanitarias básicas.

\begin{abstract}
Siempre hemos tenido internas, porque si no tendríamos que optar por pasar la noche en casa de mis padres; a ver, que en realidad, a mi madre no tiene que pasarle nada, pero nunca sabes si se va a levantar, si le va a fallar la cadera, porque tiene poca estabilidad... Procuramos que siempre haya alguien en casa. (Familia empleadora de cuidadora inmigrante, Bizkaia)
\end{abstract}

En todo caso, por parte de las entidades y servicios sociales vascos se llama la atención de la necesidad de mejora de las condiciones laborales en estos empleos y el diseño de protocolos de prevención de riesgos laborales, que sin duda ayudarán a mejorar el cuidado a las personas dependientes.

\section{Precariedad e IRRegularidad en el Sector}

DOMÉstico. Las condiciones laborales de las personas que se dedican al cuidado doméstico y de personas dependientes son calificadas como precarias, con bajos niveles de contratación, escasos salarios y sin reconocimiento de los tiempos de descanso, de las horas extras, las bajas laborales o las indemnizaciones, y se siguen identificando con el empleo de personas situadas en los estratos económicos más perjudicados de la sociedad. En los servicios sociales vascos, se reclama una mayor formalización de contratos, coberturas por bajas laborales, regularización en los convenios y vigilancia de su cumplimiento y de las condiciones laborales y salariales, además de la mejora de las posibilidades de formación para las personas que lo ejercen.

Por otro lado, aunque desde la aplicación del Real Decreto 1620/2011 la irregularidad del servicio doméstico ha descendido en la CAE, según las opiniones vertidas durante el trabajo de campo cualitativo, la formalización de un contrato de trabajo en el empleo en el servicio de cuidados en los domicilios depende en gran medida de la institución empleadora, es decir, si la contratante es una empresa o una familia, siendo esta última en la que se encuentran la mayoría de los casos de irregularidad contractual. También depende de la modalidad del trabajo ejercido, ya que se ha afirmado durante las entrevistas que el trabajo particular durante un número limitado de horas en varios hogares a la vez es aquel que se encuentra más sometido a la economía sumergida, en comparación con los hogares en los que se realiza una jornada completa o por horas para una empresa en calidad de externa, y con los casos de interinidad. 
Así, se han calificado por separado determinados aspectos concretos relativos a las condiciones laborales del sector de los cuidados. En este sentido, resulta de gran interés que la influencia de la regulación de las condiciones laborales se convierte en relativa ante la importancia de ciertas dualidades en las modalidades de empleo y la situación administrativa de las mujeres, es decir, las desigualdades que se dan entre las trabajadoras internas y externas, las que están contratadas por una empresa o directamente por una familia y las que cuentan o no con la regularidad administrativa; dualidades que se interrelacionan, e implican diferentes grados de poder de negociación con las personas empleadoras. De hecho, se dan mayores niveles de precariedad entre las mujeres que trabajan en modalidad de interna directamente para las familias y que no han accedido al primer permiso de residencia. Así, estas circunstancias van a influir en las condiciones laborales.

- Tiempo de trabajo. La distinción de las modalidades de atención interna/externa es importante a la hora de evaluar el tiempo de trabajo de cuidado en los hogares $y$, concretamente en el caso del trabajo en régimen externo, aquel realizado a jornada completa en un único domicilio o por un número limitado de horas en varios hogares durante la misma jornada laboral.

A partir de esta distinción en función del régimen, hay unanimidad de opiniones en cuanto al empeoramiento de condiciones entre las trabajadoras en régimen interno, sustentadas por el hecho de convivir con la persona cuidada. Aunque la mayor parte de las familias dicen cumplir las condiciones de horario estrictamente, las entidades sociales anuncian vulneraciones en cuanto al respeto de los horarios establecidos en la normativa, por ejemplo en el caso de las cuidadoras internas, que realizan vigilancia durante las horas de descanso nocturno.

No tiene horario laboral, porque vive en el domicilio de mis padres. Ella, una vez que hace las tareas de la casa, aunque no limpia como limpiaba mi madre... sale a dar una vuelta con mi madre, sale también por la tarde, y sábados y domingos libra, aunque está en casa, porque no tiene otra. (Familia empleadora de cuidadora inmigrante, Gipuzkoa)

- Salarios. Tanto empresas, asociaciones, entidades y servicios sociales, coinciden en que las condiciones salariales son precarias, y apelan de nuevo al reconocimiento de un sector que no se correspondería con el resto de profesiones, sobre todo si se tiene en cuenta la dedicación horaria de las personas que trabajan en él, concretamente en el caso de las trabajadoras internas. También existirían ambigüedades en el pago de remuneraciones extraordinarias y cotizaciones a la Seguridad Social.

La hora aquí está entre 10 y 11 euros. A partir de 2012, es obligado dar de alta en la Seguridad
Social, aunque sea una hora: es un poco absurdo, porque cuesta más dar de alta una hora que el sueldo. Hace dos años, me regía por la ley, pero consideramos que tiene unos precios muy bajos, a unos 5,33 euros la hora. Entonces me puse en comunicación con otras entidades, y hemos redactado una tabla de precios orientativa, y por menos de ese precio no derivamos, aquí no se regatea, el servicio doméstico hay que valorarlo, se necesita reconocimiento del sector. [...] Por interna, el precio mínimo es de 900 euros por una persona, 1.000 por dos, por 14 pagas enteras, y la Seguridad Social. (Persona técnica de entidad social, Bizkaia)

- Actividades ejercidas. Hay que volver a hablar, en este caso, de desigualdades entre los modelos interno y externo, tenencia o no de un contrato, y contratación por parte de una familia o de un servicio formal. De esta manera, se ha apreciado durante las entrevistas una variación entre las exigencias de las empresas, más vinculadas al trabajo de cuidado y acompañamiento de personas dependientes, y las de los hogares, en las que el trabajo se asocia tanto a la atención personal como al cuidado de la casa y las tareas domésticas propias del mantenimiento de la familia.

Hacen todo: [trabajo] doméstico y cuidar a mi madre, porque ella necesitaba todo. Además, ella no daba ninguna guerra y podían limpiar en casa, pero nunca más de 8 horas; de las cenas, no se ocupaba. (Familia empleadora de cuidadora inmigrante, Gipuzkoa)

- Salud laboral. Dolencias tanto físicas como psíquicas, sobrecargas musculares, cefaleas, estrés y ansiedad son problemas comunes expresados en las charlas con las cuidadoras inmigrantes. Las causas de estos padecimientos son, definitivamente, el tipo de trabajo que desempeñan y la duración de la jornada laboral, con actividades que suponen un sobreesfuerzo físico y psicológico difícil de asumir, por lo que se vuelven a reclamar la introducción de protocolos de Prevención de Riesgos Laborales en la normativa del sector doméstico.

Yo he sufrido problemas psíquicos. Porque cuando trabajas de lunes a lunes, de 9 de la mañana a 9... Llegó un momento que sentí que me faltaba el aire, y me desmayé. Físicamente, tuve problemas por tener que levantar a la persona a la que cuidaba, al bajarla de la silla... Vives con el dolor en la columna y el miedo a que la señora se cayese. (Mujer cuidadora inmigrante, Nicaragua).

\section{- La importancia de la formación profesional.}

Para las mujeres inmigrantes entrevistadas, la formación profesional en los cuidados es de vital importancia, $y$ en muchas ocasiones han sido ellas mismas las que han buscado sus propios recursos formativos, ofrecidos por las entidades sociales a las que acuden en busca de asesoramiento y acompañamiento en sus procesos migratorios. Por su parte, las asociaciones y entidades sociales, que coinciden con la importancia de la 
especialización para el ejercicio de las labores de cuidado a personas dependientes, se lamentan del hecho de que las cuidadoras no lleguen a adquirirla en la mayoría de los casos, por la dificultad de conciliación con el empleo, o la merma del acceso a los recursos cuando no se cuenta con la regularidad administrativa.

La formación es importantísima, y no se hace: Lanbide [el Servicio Vasco de Empleo] se dedica a la formación, pero si una persona que se dedica a los cuidados no puede conciliar, ¿Cómo se va a dedicar a formarse? No tiene tiempo... Y en otros centros, cuesta dinero y no se puede pagar. (Persona técnica de asociación, Gipuzkoa)

- Situaciones de abuso y maltrato. Aunque de los resultados obtenidos no se puede establecer una conclusión significativa sobre la frecuencia de situaciones de acoso y maltrato, sí puede decirse que la falta de documentación de las mujeres cuidadoras es un elemento de importancia central a la hora de medir la vulnerabilidad ante estas situaciones, debido a la desprotección legal derivada de la irregularidad administrativa o al simple miedo a la hora de tramitar denuncias. Así, durante el trabajo de campo se ha señalado que uno de los recursos sociales más demandados es el de asesoramiento legal que defienda a estas mujeres de situaciones injustas.

Se dan los malos tratos sobre todo cuando no tienes papeles. Cuando yo vine aquí, las condiciones eran inhumanas: sin derecho a sentarse, a hablar con el móvil, de lunes a lunes de 9 de la mañana a 9, no podía ir a comprar, porque no podía dejar a la persona sola, el siguiente era de 6 de la tarde a las 10 de la mañana. No me dejaban lavar ropa, que lavara una vez al mes, aunque ahora estoy mejor, en otro no me dejaban utilizar el agua caliente... (Mujer cuidadora inmigrante, Nicaragua)

\section{Conclusiones}

El fin último del recorrido realizado a través del contexto que envuelve a la migración femenina, las familias con personas dependientes y los recursos públicos de atención, responde al análisis de la hipótesis principal construida desde el primer planteamiento de este ejercicio de investigación: el padecimiento de procesos de discriminación múltiple por parte de las mujeres migradas a Euskadi que trabajan en actividades domésticas y de cuidados a personas dependientes en los hogares.

A lo largo de este proceso, la primera de las conclusiones que se han alcanzado es que la situación vital de estas mujeres depende de múltiples factores externos a ellas mismas, como la regulación de la extranjería, las políticas públicas aplicadas en relación a la atención a personas dependientes, las necesidades de las familias beneficiarias de estas políticas, y las condiciones laborales del sector de los cuidados realizados en el ámbito doméstico, factores que generan, necesariamente, un conjunto de otras conclusiones que permiten aceptar dicha hipótesis.

En primer lugar, la desestabilización del modelo tradicional de familia, el envejecimiento de la población, y el reparto - todavía desigualitario- de responsabilidades entre las personas que componen el núcleo familiar, que han derivado en graves problemas de conciliación entre tiempo de trabajo remunerado, no remunerado y personal, y que pone en evidencia la necesidad de la creación de servicios e incorporación de personas que ejerzan labores hasta el momento consideradas 'no productivas'.

Así, la creación de estos servicios viene determinada por el modelo de protección social instaurado en cada territorio, que en el caso de Euskadi se acercaría al denominado modelo mediterráneo (Van Hooren, 2012), caracterizado por un desarrollado sistema de prestaciones económicas sometidos a escasos controles, en el que las familias recurren a las personas cuidadoras que prestan en los hogares labores domésticas y de cuidado. No obstante, hay que decir que la estadística indica una relativa evolución sobre esta tesis aportada por la bibliografía consultada y el marco cualitativo, ya que las cifras indican una ralentización del recurso de las personas con dependencia a los servicios domiciliarios.

En este contexto, ante la necesidad de servicios de cuidado en los hogares, la división sexual del trabajo ha devenido en una división internacional o etnoestratificación (Anderson, 2000) del trabajo reproductivo, que implica el 'reparto' de profesiones en función de la nacionalidad de las personas, y que convierte al sector de los cuidados en los domicilios en prácticamente la única posibilidad laboral que tienen parte de las mujeres migradas. Estas mujeres, con un perfil determinado en lo que se refiere a su situación familiar, emigran de sus países de origen, dejando a cargo de otras mujeres a su propia descendencia, para ejercer labores de cuidado de manera remunerada, en muchas ocasiones, en el principio de su proceso migratorio, en régimen de interinidad y en la economía sumergida, al menos hasta poder demostrar un registro de tres años en el padrón municipal, momento en el que podrían solicitar la primera autorización de residencia si cuentan con un contrato de trabajo.

De esta manera, la discriminación sufrida por parte de la migración femenina, aquella que ejerce su trabajo en los domicilios al cuidado del hogar y de personas dependientes, radica en dicho reparto, y en las especiales condiciones que se dan en el sector doméstico, de carácter femenino, y por tanto precario e invisible. Así, aunque a partir de la última regulación del empleo doméstico, la irregularidad ha descendido, siguen existiendo razones para pensar en la invisibilidad y la falta de control, y en las grandes desigualdades en las 
condiciones de trabajo en función de la institución contratante y el régimen interno o externo, que van a condicionar la posibilidad de solicitar un empadronamiento, un contrato de trabajo y el acceso a recursos sociales en igualdad al resto de la población.
Por último, cabe destacar que en dicha regulación no se contempla la protección ante riesgos laborales ni la obligación de prestar formación profesional, dos cuestiones que, sin duda, mejorarían la calidad en el empleo de las personas que lo ejercen y el cuidado a las personas dependientes.

\section{Bibliografía}

ANDERSON, B. (2000): Doing the Dirty Work, Londres, Zed Press.

BRIONES, E. et al. (2014): "Percepción de las trabajadoras inmigrantes del servicio doméstico sobre los efectos de la regulación del sector en España”, Gaceta Sanitaria, vol. 28, no 2, págs. 109-115.

DEPARTAMENTO DE EMPLEO Y POLÍTICAS SOCIALES (s/d): Encuesta de Condiciones de Trabajo, VitoriaGasteiz, Gobierno Vasco.

EUROSTAT (2014): European Labour Force Survey, Luxemburgo, Comisión Europea.

EUSTAT (2014): Encuesta de la Población en Relación con la Actividad, Vitoria-Gasteiz, Gobierno Vasco.

GARCÍA SAINZ, C.; SANTOS PÉREZ, M. L.; y VALENCIA OLIVERO, N. Y. (2014): “La construcción social del mercado laboral doméstico en España a comienzos del siglo XXI", Cuadernos de Relaciones Laborales, vol. 32, no 1, págs. 101131 [rhttp://revistas.ucm.es/index.php/CRLA/ article/download/44715/42157>].

GIL ARAUJO, S.; y GONZÁLEZ, T. (2012): “Migraciones, género y trabajo en España. El tránsito obligado de las trabajadoras inmigrantes por el empleo de hogar", Mora (Buenos Aires), vol. 18, no 2, págs. 1-11 [khttp:// www.scielo.org.ar/scielo.php?pid=S1853001 X2012000200004\&script=sci_arttext $\rangle]$.

HRŽENJAK, M. (2011): “The regulation of paid domestic work: A win-win situation or a reproduction of social inequalities?", en DAHL, H.; KERÄNEN, M.; y KOVALAINEN, A. (eds.), Europeanization, Care and Gender: Global Complexities, Nueva York, Palgrave MacMillan, págs. 59-80.
IBÁÑEZ, J. (1979): Más allá de la sociología. El grupo de discusión: técnica y crítica, Madrid, Siglo XXI.

ESPAÑA (2011): “Real Decreto 1620/2011, de 14 de noviembre, por el que se regula la relación laboral de carácter especial del servicio del hogar familiar", Boletín Oficial del Estado, ํㅜ 277, 17-11-11, págs. 119.046119.057 [ [http://www.boe.es/buscar/doc. php?id=BOE-A-2011-17975'].

- (2006): “Ley 39/2006, de 14 de diciembre, de Promoción de la Autonomía Personal y Atención a las Personas en Situación de Dependencia", Boletín Oficial del Estado, no 299, 15-12-06, págs. 44.142-44.156 [<http://www.boe.es/ buscar/doc.php?id=BOE-A-2006-21990>].

- (2000): “Ley Orgánica 4/2000, de 11 de enero, sobre Derechos y Libertades de los Extranjeros en España y su Integración Social”, Boletín Oficial del Estado, n- 10, 12-1-00, págs. 1.139-1.150 [khttp://www.boe.es/buscar/ doc.php?id=BOE-A-2000-544)].

- (1985): “Real Decreto 1424/1985, de 1 de agosto, por el que se regula la relación laboral de carácter especial del Servicio del Hogar Familiar", Boletín Oficial del Estado, nำ193, 13-8-85, págs. 25.617-25.618 [<http://www.boe.es/ buscar/doc.php?id=BOE-A-1985-17108>].

LEÓN, M. (2013): “A real job? Regulating household work: The case of Spain", European Journal of Women's Studies, vol. 20, nํㅡ 2, págs. 170-188.

MARTÍNEZ-BUJÁN, R. (2014): “Los modelos territoriales de organización social del cuidado a personas mayores en los hogares", Revista Española de Investigaciones Sociológicas, $\mathrm{n}-145$, 
págs. 99-124 [<http://dx.doi.org/10.5477/cis/ reis.145.99'].

- (2011): "La reorganización de los cuidados familiares en un contexto de migración internacional”, Cuadernos de Relaciones Laborales, vol. 29, no 1, págs. 93-123 [<http://www.siis.net/ documentos/ficha/201033.pdf/].

- (2008): "Los beneficios de la inmigración al Estado de bienestar. Mujeres inmigrantes en el sector doméstico de cuidados", en IZQUIERDO ESCRIBANO, A. (coord.), El modelo de inmigración y los riesgos de exclusión, Madrid, Fundación Foessa, págs. 259-290.

NOGUEIRA, J.; y ZALAKAIN, J. (2015): La discriminación múltiple de las mujeres inmigrantes trabajadoras en servicios domésticos y de cuidados en la Comunidad Autónoma de Euskadi, Emakunde-Instituto Vasco de la Mujer [<http://www.emakunde.euskadi.eus/ u72-contema/es/contenidos/informacion/ publicaciones_subvencionadas2/es_def/ adjuntos/beca.2014.2.mujeres.inmigrantes. trabajadoras.servicios.domesticos.pdf〉].

OROZCO, A. (2007): “Cadenas globales de cuidado", serie: Género, Migración y Desarrollo, nํ 2, Santo Domingo, Instituto Internacional de Investigaciones y Capacitación de las Naciones Unidas [<http://mueveteporlaigualdad.org/ publicaciones/cadenasglobalesdecuidado orozco.pdf $\rangle]$.

ÓRGANO ESTADÍSTICO ESPECÍFICO DEL DEPARTAMENTO DE EMPLEO Y POLÍTICAS SOCIALES (2014): Estadística de Demanda de Servicios SocialesEncuesta de Necesidades Sociales, VitoriaGasteiz, Gobierno Vasco.

- (2010): Encuesta de Población Inmigrante en Euskadi, Vitoria-Gasteiz, Gobierno Vasco.

- (s/d): Censo del Mercado de Trabajo, Vitoria-Gasteiz, Gobierno Vasco.

PAÍS VASCO (2011): “Ley 4/2011, de 24 de noviembre, de modificación de la Ley para la Garantía de Ingresos y para la Inclusión Social”, Boletín Oficial del País Vasco, nํㅜ 233, 12-12-11 [shttps://www.euskadi.eus/r47-bopvapps/es/ bopv2/datos/2011/12/1105924a.shtml>].
- (2008): "Ley 18/2008, de 23 de diciembre, para la Garantía de Ingresos y para la Inclusión Social”, Boletín Oficial del País Vasco, nㅜ 250, 31-12-08 [<https://www.euskadi.eus/r47-bopvvaci/es/ bopv2/datos/2008/12/0807235a.shtml〉].

- (2008): "Ley 12/2008, de 5 de diciembre, de Servicios Sociales", Boletín Oficial del País Vasco, no 246, 24-12-08, págs. 31.840-31.924 [shttps://www.euskadi.eus/r47-bopvapps/es/ bopv2/datos/2008/12/0807143a.shtmls].

PARELLA, S. (2003): Mujer, inmigrante y trabajadora: la triple discriminación, Barcelona, Anthropos.

PAVLOU, V. (2011): "The case of female migrant domestic workers in Europe: Human rights violations and forward looking strategies", Yearbook of Humanitarian Action and Human Rights, no 9, págs. 67-84 [<https://www.academia. edu/1837052/Title_The_Case_of_Female_ Migrant_Domestic_Workers_in_Europe Human_Rights_Violations_and_Forward_ Looking_Strategies〉].

PLA-JULIÁN, I.; y GIMÉNEZ-MORENO, R. (2012): “Deficiencies and limitations on current household employment in Spain", Journal of Social Sciences, vol. 33, n- 3, págs. 323-332 [<http:// www.krepublishers.com/o2-Journals/JSS/JSS33-0-000-12-Web/JSS-33-3-000-12-Abst-PDF/ JSS-33-3-323-12-1410-Pla-Julian/JSS-33-3-32312-1410-Pla-Julian-Tx\%5B6\%5D.pdf >].

PLATERO, R. (2012): “¿Son las políticas de igualdad de género permeables a los debates sobre la interseccionalidad? Una reflexión a partir del caso español", Revista del CLAD Reforma y Democracia, no 52 [<http://www.redalyc.org/ articulo. $0 a$ ? $\left.i d=357533684005^{\prime}\right]$.

TESORERÍA GENERAL DE LA SEGURIDAD SOCIAL (2009-2014): Registro de afiliaciones a la Seguridad Social, Madrid, Ministerio de Empleo y Seguridad Social.

VAN HOOREN, F. J. (2012): "Varieties of migrant care work: Comparing patterns of migrant labour in social care", Journal of European Social Policy, vol. 22, nํㅜ 2, págs. 132-147. 